\title{
Phonological Skills in Korean-English Bilingual Children: Phonetic Inventory and Segmental Accuracy
}

\author{
Jae-Hyun Kim*, Elaine Ballard², Clare McCann² \\ 'Macquarie University, Australia; ${ }^{2}$ University of Auckland, New Zealand
}

Purpose: The purpose of this study was to describe phonological skills in Korean-English bilingual children aged between 3;0 and 7;11. The findings can contribute to our knowledge of bilingual children's phonological development, facilitating the clinical assessment procedures for bilingual children with suspected speech sound disorders.

Methods: Single word samples were collected and were analysed for phonetic inventory and segmental accuracy. The findings were compared against the available monolingual studies.

Results: The age of mastery of phonological systems was similar to that expected in monolingual children in both languages. However, there were considerable differences in the trajectory towards in their phonological development in both languages.

Conclusions: Phonological development in KEB children was qualitatively different from respective monolingual children. The qualitative differences in KEB children can be attributed to the cross-linguistic interaction between the two phonological systems. Cross-linguistic interactions reflect reorganisation of the two phonological systems wherein a dynamic process of re-specifying phonemes and their realisation rules for each language takes place. The clinical implications are discussed.

Keywords: Speech sound disorder, Phonological development, Bilingualism

\section{INTRODUCTION}

Speech sound disorders of unknown origin (henceforth SSD) are common in childhood [1-3] and characterised by a clinically significant deviation from typical phonological development that is not accounted for by an impairment in sensory, motor or structural functions [4,5]. Because children with SSD do not have an identifiable aetiology, knowledge of typical phonological development is essential in diagnosing SSD. Age of acquisition of speech sounds and segmental accuracy in typical phonological development are among the clinically pertinent information [6-10]. There is a lack of such clinically relevant information for bilingual children. This presents as a significant challenge to speech-language pathologists (SLPs) assessing bilingual children with a suspected SSD [11-14].

\section{Bilingual phonological development: comparison with monolingual children}

One way to address this issue may be to explain how bilingual phonological develop-

(

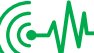

Received: April 2, 2017

Revision: August 29, 2017

Accepted: August 30, 2017

Correspondence:

Jae-Hyun Kim

Macquarie University, North Ryde, NSW 2109, Australia

Tel: +61 298509805

E-mail: jae-hyun.kim@mq.edu.au

(C) 2017 The Korean Association of SpeechLanguage Pathologists

This is an Open Access article distributed under the terms of the Creative Commons Attribution Non-Commercial license (http:// creativecommons.org/licenses/by-nc/4.0/) which permits unrestricted non-commercial use, distribution, and reproduction in any medium, provided the original work is properly cited. 
ment is different from monolingual phonological development, thereby predicting, or at least describing with reasonable accuracy, the rates and patterns of bilingual phonological development based on the available monolingual normative data. The Interactional Dual Systems (IDS) model suggests bilingual children have two separate phonological systems that are interdependent of each other in development [15-17]. Interdependence is defined as "the systematic influence of grammar of one language on the grammar of the other language during acquisition, causing differences in a bilingual's patterns and rates of development in comparison with a monolingual's" [18]. Interdependence between two phonological systems can manifest in three different ways; acceleration, deceleration and transfer $[15,17,18]$. Acceleration occurs when a feature of grammar in one language emerges earlier in bilingual children than would be the expected in monolingual children [18]. Regarding deceleration, Paradis and Genesee [18] proposed that having to master two languages "slow[s] down the acquisition process in bilinguals, causing them to be behind monolinguals in their overall progress.... These two hypothesised manifestations have received some support in the literature. So and Leung [19] suggested that deceleration in bilingual children's phonological development should be expected because bilingual children receive proportionately less exposure to each of their languages. Goldstein and Gildersleeve-Neumann [20] added that bilingual children likely use some developing sounds and syllable shapes less frequently than monolingual children, which leads to slower mastery of the phonologies. Bunta, Fabiano-Smith [21] and Gildersleeve-Neumann, Kester [22] found that bilingual children obtain lower percentage of consonants correct (PCC) scores than their monolingual counterparts. On the other hand, Fabiano-Smith and Barlow [23] found no evidence of deceleration and the bilingual children acquired the phonetic inventories at the same rate as monolingual children in both of their languages. Other studies also reported that bilingual phonological development is commensurate with or even shows an accelerated rate of development [24-27]. As Hambly and colleagues' systematic review found, the evidence regarding acceleration or deceleration is inconclusive [28].

Regarding the third hypothesised manifestation, transfer, the IDS model states that "consonants and/or vowels that are specific to one language will transfer to productions of the other language" [15]. The transfer within the IDS model specifically relates to language-specific speech sounds. This differs from how transfer is discussed in the literature of adult second language acquisition [29,30]. The evidence for segmental transfer, as described in the IDS model, is equivocal. Previous studies found that such segmental transfer in bilingual children is uncommon or does not occur systematically [15,24,31-34]. One of the few exceptions is Gildersleeve-Neumann and Wright [35] who reported that transfer occurred frequently in Russian-English bilingual children and attributed this finding to language dominance and perceptual saliency of the transferred segments.

\section{Bilingual phonological development: cross-linguistic effects} The qualitative and quantitative differences in phonological development between monolingual and bilingual children have been attributed to cross-linguistic interactions between the two phonological systems [15-17,23,36]. Based on the previous literature $[15,17,37]$ the rates and patterns of phonological development in bilingual children that are different from those in monolingual children are taken as manifestations of cross-linguistic effects in the current article. The starting point of most approaches to explain cross-linguistic effects is to consider the relative complexity between the two phonological systems $[26,32,34,38,39]$. Empirical evidence suggests that cross-linguistic effects in bilingual language development likely manifests at the points of structural overlap [36,40,41]. Structural overlap hypothesises that cross-linguistic effects occur at the interface between two modules of grammar and if language A has one pattern for a target structure, but language $B$ has more than one pattern for that structure [41]. The current article applies structural overlap to bilingual phonological development. The interface between two modules of grammar is concerned with the phonetics-phonology interface in the case of phonological development. Structural overlap in the acquisition of consonants can be considered, for example, with /1/ in bilingual children exposed to English and Korean. In English, /l/ is realised as [1], whereas Korean /1/ can be realised as [1] or $[\mathrm{r}]$ depending on word position, creating structural overlap between the two languages. We would expect delayed mastery of the allophonic variant, [r], in Korean, because the structural pattern of English would influence these bilingual children to use its matching pattern, [1].

\section{The current study}

The primary aim of the current study was to provide detailed descriptions of phonological skills in Korean-English bilingual (KEB) children growing up in New Zealand. To date there are only a handful of studies on KEB children's phonological de- 
velopment, most of which are case studies [33,42,43]. As age of acquisition of speech sounds and segmental accuracy have clinical relevance, the descriptions of phonological skills provided in this article focus on these two measures. A secondary aim of the current study was to compare phonological skills in KEB to their respective monolingual populations using the existing studies of monolingual English-speaking (ME) and monolingual Korean-speaking (MK) children. We first describe phonological features of each language and phonological skills in ME and MK children.

\section{Phonological features of Korean and English}

Table 1 compares Korean and English phonologies. Korean stops and affricates have a three-way distinction by the degree of tenseness and aspiration [44]. The lax segments (/p, t, k, ts/ are weak and breathy, while the aspirated segments $\left(/ \mathrm{p}^{\mathrm{h}}, \mathrm{t}^{\mathrm{h}}, \mathrm{k}^{\mathrm{h}}\right.$, $\left.\mathrm{ts}^{\mathrm{h}} /\right)$ are strongly aspirated. Tense segments $\left(/ \mathrm{p}^{*}, \mathrm{t}^{*}, \mathrm{k}^{*}, \mathrm{ts} /\right)$ are characterised by greater glottal tension compared to the other segments $[45,46]$. This three-way distinction is phonemic in Korean. Kim [47], [48] conducted a series of articulatory and acoustic studies and suggested that the Korean affri-

Table 1. Comparison of Korean and English phonologies (New Zealand English is described here)

\begin{tabular}{|c|c|c|}
\hline & Korean & English \\
\hline \multicolumn{3}{|l|}{ Consonants } \\
\hline Stops & 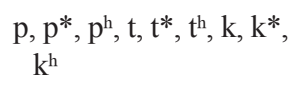 & $\mathrm{p}, \mathrm{b}, \mathrm{t}, \mathrm{d}, \mathrm{k}, \mathrm{g}$ \\
\hline Affricates & $\mathrm{ts}, \mathrm{ts}^{*}, \mathrm{ts}^{\mathrm{h}}$ & tf, ds \\
\hline Fricatives & $\mathrm{s}, \mathrm{s}^{*}, \mathrm{~h}$ & $\mathrm{f}, \mathrm{v}, \theta, \partial, \mathrm{s}, \mathrm{z}, \int, \mathrm{z}, \mathrm{h}$ \\
\hline Nasals & $\mathrm{n}, \mathrm{m}, \mathrm{y}$ & $\mathrm{n}, \mathrm{m}, \mathrm{y}$ \\
\hline Liquids & 1 & $1, \mathrm{I}$ \\
\hline Glides & No phonemic glides & $\mathrm{j}, \mathrm{w}$ \\
\hline \multicolumn{3}{|l|}{ Vowels } \\
\hline Monophthongs & $\mathrm{i}, \mathrm{e}, \dot{\mathrm{i}}, \Lambda, \mathrm{a}, \mathrm{u}, \mathrm{o}$ & $\begin{array}{l}\mathrm{i}, \mathrm{I}, \mathrm{e}, æ, \mathrm{u}, \mho, \mathrm{p}, 3, \curvearrowright, \Lambda, \\
\quad \mathrm{a}, \text { ə }\end{array}$ \\
\hline Diphthongs & $\begin{array}{l}\text { ui, ie, ue, ii, is, us, ia, } \\
\text { ua, iu, io }\end{array}$ & 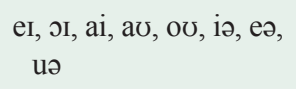 \\
\hline \multicolumn{3}{|l|}{ Syllables } \\
\hline Clusters & $\begin{array}{l}\text { No consonant clusters } \\
\text { within a syllable }\end{array}$ & $\begin{array}{l}\text { Up to three consonants as } \\
\text { onset and four } \\
\text { consonants in coda } \\
\text { position }\end{array}$ \\
\hline Onset & $\begin{array}{l}\text { All consonants permitted } \\
\text { except for } / \mathrm{y} /\end{array}$ & $\begin{array}{l}\text { All consonants permitted } \\
\text { except for } / \mathrm{y} /\end{array}$ \\
\hline Coda & $\begin{array}{l}\text { Only lax stops, nasals and } \\
\text { liquid permitted }\end{array}$ & $\begin{array}{l}\text { All consonants permitted } \\
\text { except for /. }, \mathrm{j}, \mathrm{w}, \mathrm{h} /\end{array}$ \\
\hline
\end{tabular}

cates are alveolar. The alveolar placement of articulation for the Korean affricates has also been supported by a later Magnetic Resonance Imaging (MRI) study investigating the displacement of the tongue and vertical larynx movement [49]. The current article adopts the view that the Korean affricates are alveolar (/ts, $\left.\mathrm{ts}^{*}, \mathrm{ts}^{\mathrm{h}} /\right)$.

Between voiced segments, the Korean lax series can be realised as their voiced allophones [46]. On the other hand, in English, voicing results in a phonemic contrast for English obstruents, such that the change in voicing is associated with a change in meaning. The degree of aspiration in English stops is associated with allophonic variants of the same segments and thus can vary depending on the distribution [50].

Korean alveolar fricatives only have a two-way distinction classified by the degree of tenseness. The lax fricative, /s/, is never voiced but can be palatalised before high front vowel and slackened intervocalically [44]. The other fricative, $/ \mathrm{h} /$, is the only glottal sound in Korean and it is often dropped between voiced segments in natural speech [46]. The English fricatives could be said to be more complex than Korean at least in terms of their place of articulation.

The contrasts and phonotactic constraints on nasal consonants are similar between the two languages. The Korean liquid is realised as [l] in word final position and in a sequence of two liquids at a syllable boundary (e.g. /ol.la.ka.ta/), but as [r] in word initial position or intervocalically. No native Korean words begin with the liquid but English loanwords do [44,46]. The rhotic consonant, / $\mathrm{x} /$, is specific to English. In non-rhotic varieties of the English language, such as New Zealand English, /./ following a vowel is not produced.

On vowels, English has the phonemic lax-tense distinction (e.g. live vs. leave), which is not found in Korean. There are variations in the way Korean vowels are described in the literature. Table 1 presents the contemporary vowel system in Korean. Previously observed $/ \varepsilon$ / has now been merged with /e/ $[44,51]$ and the front rounded vowels, /y/ and /ø/, have been diphthongised to [wi] and [we], respectively $[46,52,53]$. The Korean diphthongs are phonetically realised as a sequence of glide and vowel. For example, /ui/ is realised as [wi] and /ie/ as [je]. In natural speech, post-consonantal glides can be dropped [54], so that toilet can be pronounced either as [hwa. dzay.sil] or [ha.dzay.sil]. The glides in Korean phonology are not independent phonemes [52], while they are phonemes in English.

Korean does not permit consonant clusters within a syllable, whereas complex onset and coda are observed in English. 
In Korean, a sequence of two consonants can occur at syllable boundary (e.g. / $\mathrm{ts}^{\mathrm{h}} \mathrm{im} . \mathrm{te} /$ ). A sequence of the same consonants is also permitted in the case of $/ \mathrm{m} /, / \mathrm{n} /$ or $/ \mathrm{l} /$ at syllable boundary (e.g. / $\mathrm{mm} \cdot \mathrm{ma} /$ ). Korean stops in word final position are always unreleased and unaspirated. The slight puff of air realised in English word final stops is not observed in Korean $[44,46]$.

\section{Phonological skills in monolingual English- and Korean- speaking children}

In the current article, the term, phonological skills, refers to the phonetic inventory and segmental accuracy. While these measures of phonological skills have been used widely in research and clinically, there are considerable differences in the way they have been defined $[8,55]$. In this section, we define these measures as presented in this article.

Consonants produced at least once spontaneously or in imitation are included in the phonetic inventory [6]. Phonetic inventory is an independent phonological measure, which does not take the target productions into consideration [56]. The emphasis on whether the child can produce the speech sounds rather than whether the child can produce the speech sounds correctly. This is distinguished from phonemic inventory, a relational phonological measure, which identifies the speech sounds produced correctly [56]. To establish the age of acquisition of speech sounds, Dodd, Holm [6] used the $90 \%$

Table 2. Age of acquisition of consonants in monolingual children

\begin{tabular}{|c|c|c|}
\hline Age & English & Korean \\
\hline \multirow[t]{4}{*}{$3 ; 0-3 ; 5$} & $\mathrm{p}, \mathrm{b}, \mathrm{t}, \mathrm{d}, \mathrm{k}, \mathrm{g}$ & $\mathrm{p}(\mathrm{SI}), \mathrm{p}^{*}, \mathrm{p}^{\mathrm{h}}, \mathrm{t}^{*}$ \\
\hline & $\mathrm{m}, \mathrm{n}, \mathrm{n}$ & \\
\hline & $\mathrm{f}, \mathrm{v}, \mathrm{s}, \mathrm{z}, \mathrm{h}$ & $\mathrm{h}$ \\
\hline & $1, \mathrm{w}, \mathrm{j}$ & \\
\hline $3 ; 5-3 ; 11$ & t & $\mathrm{p}(\mathrm{SF})$ \\
\hline \multirow[t]{4}{*}{$4 ; 0-4 ; 5$} & & $\mathrm{t}(\mathrm{SI}), \mathrm{k}(\mathrm{SI})$ \\
\hline & & $\mathrm{m}(\mathrm{SF}), \mathrm{n}(\mathrm{SF})$ \\
\hline & 3 & \\
\hline & ds & ts, $\mathrm{ts}^{*}, \mathrm{ts}^{\mathrm{h}}$ \\
\hline \multirow[t]{2}{*}{$4 ; 6-4 ; 11$} & & $\mathrm{k}(\mathrm{SF}), \mathrm{k}^{\mathrm{h}}$ \\
\hline & & $\eta$ \\
\hline $5 ; 0-5 ; 5$ & $\int$ & \\
\hline $5 ; 6-5 ; 11$ & & $1(\mathrm{SI})$ \\
\hline $6 ; 0-6 ; 5$ & I & \\
\hline \multicolumn{3}{|l|}{$6 ; 6-6 ; 11$} \\
\hline $7 ; 0$ & $\theta$, ठ & $\mathrm{s}, \mathrm{s}^{*}$ \\
\hline
\end{tabular}

criterion based on the research findings that approximately $10 \%$ of the paediatric population have SSD. That is, a consonant present in $90 \%$ of children's phonetic inventory in an age group is considered mastered for that age group. This criterion is used in the current study. Table 2 compares the age of acquisition of consonants between the normative studies of ME children [6] and MK children [57]. Kim and Pae [57] specified syllable position for the six consonants that are permitted in either syllable initial or syllable final position. For $/ \mathrm{k}^{*} /, / \mathrm{t}^{\mathrm{h}} /$, syllable initial $/ \mathrm{m} /$, syllable initial /n/, syllable final $/ \mathrm{t} /$ and syllable final /1/, Kim and Pae [57] do not provide the age of mastery (i.e. correctly produced by $90 \%$ of the children in the age group) but reported that $75 \%$ of the children in the age group of 3;0-3;5 correctly produced these speech sounds. According to earlier studies, [58-60], they are mastered before the age of four years.

Generally, stops are acquired earlier than other consonant classes in both languages. MK children tend to acquire speech sounds earlier in syllable initial position than in syllable final position, with the exception of the liquid. The liquid in syllable initial position, which is realised as [ $\mathrm{r}$ ], is mastered only after 5;6. There are noticeable differences in shared speech sounds in terms of the age of acquisition. The most striking difference in segmental acquisition between the two groups of monolingual children is the age of acquisition of /s/. While ME children master /s/ at the of three years, it is mastered after the age of six years in MK children [57,61].

Segmental accuracy is calculated by means of a relational analysis in which the child's productions are analysed against the target responses. PCC is calculated by dividing the total number of consonants by the number of correctly produced consonants and converting into a percentage score. Similarly, percentage of vowels correct (PVC) is also used, albeit to a

Table 3. Percentage of consonants correct in monolingual children (standard deviations in the parentheses)

\begin{tabular}{lll}
\hline Age & \multicolumn{1}{c}{ English } & \multicolumn{1}{c}{ Korean } \\
\hline $3 ; 0-3 ; 5$ & $82.11(13.0)$ & $82.36(11.03)$ \\
$3 ; 6-3 ; 11$ & & $88.08(7.37)$ \\
$4 ; 0-4 ; 5$ & & $92.19(7.47)$ \\
$4 ; 6-4 ; 11$ & $90.37(9.05)$ & $93.71(7.35)$ \\
$5 ; 0-5 ; 5$ & & $94.38(5.86)$ \\
$5 ; 6-5 ; 11$ & & $96.76(3.81)$ \\
$6 ; 0-6 ; 5$ & & $97.29(3.51)$ \\
$6 ; 6-6 ; 11$ & $95.86(5.2)$ & Not included \\
\hline
\end{tabular}


lesser extent in older children. ME children master all vowels by the age of three years $[6,62-64]$ with PVC scores above 95\% by the age of three years. Table 3 compares the age group mean PCC scores between ME children and MK children [6, 57 , respectively]. The scores increase and the standard deviations become smaller with age in both studies. There is a general trend for higher scores in MK children, based on these two studies. Detailed information about the mean PVC scores across age groups (and the age of acquisition of vowels) in MK children is not available. The available studies suggest that the age of mastery of vowels in MK children is comparatively late, particularly for diphthongs. MK children still make some vowel errors at the age of four years [65] and diphthongs are not mastered until after the age of five years [60,66]. However, post-consonantal glide deletion in Korean is not uncommon in natural speech [54].

\section{METHODOLOGY}

\section{Participants}

The current study set out to recruit typically developing KEB children aged between 3;0 and 7;11 in New Zealand. Children were considered bilingual if (a) they were receiving regular and consistent input in both English and Korean and (b) the parents reported that their children were bilingual. Children were considered typically developing, if they did not have any

Table 4. Characteristics of the participants

\begin{tabular}{|c|c|c|c|c|c|c|c|c|c|c|c|}
\hline Participant & Age & Gender & $\begin{array}{l}\text { Birth country } \\
\text { (age of arrival) }\end{array}$ & $\begin{array}{c}\text { Age of } \\
\text { English } \\
\text { exposure }\end{array}$ & $\begin{array}{c}\text { Proportion } \\
\text { of } \\
\text { language } \\
\text { exposure }\end{array}$ & Participant & Age & Gender & $\begin{array}{l}\text { Birth country } \\
\text { (age of arrival) }\end{array}$ & $\begin{array}{c}\text { Age of } \\
\text { English } \\
\text { exposure }\end{array}$ & $\begin{array}{c}\text { Proportion } \\
\text { of } \\
\text { language } \\
\text { exposure }\end{array}$ \\
\hline $3 \mathrm{~A}$ & $3 ; 0$ & M & New Zealand & 0 & 13.00 & $5 G$ & $5 ; 6$ & $M$ & New Zealand & 48 & 1.11 \\
\hline 3B & $3 ; 1$ & M & New Zealand & 36 & 7.17 & $5 \mathrm{H}$ & $5 ; 6$ & $\mathrm{~F}$ & New Zealand & 60 & 1.28 \\
\hline $3 C$ & $3 ; 1$ & M & New Zealand & 34 & 4.06 & 51 & $5 ; 6$ & $\mathrm{~F}$ & New Zealand & 0 & 2.38 \\
\hline $3 D$ & $3 ; 2$ & $\mathrm{~F}$ & New Zealand & 0 & 0.69 & $5 \mathrm{~J}$ & $5 ; 8$ & M & New Zealand & 18 & 0.37 \\
\hline $3 \mathrm{E}$ & $3 ; 4$ & M & Korea (35) & 36 & 1.44 & $5 K$ & $5 ; 8$ & $\mathrm{~F}$ & New Zealand & 0 & 1.28 \\
\hline $3 F$ & $3 ; 6$ & $\mathrm{~F}$ & New Zealand & 0 & 3.09 & $5 \mathrm{~L}$ & $5 ; 10$ & $\mathrm{~F}$ & Korea (45) & 36 & 0.59 \\
\hline $3 G$ & $3 ; 7$ & $\mathrm{~F}$ & Korea (12) & 41 & 4.06 & $5 \mathrm{M}$ & $5 ; 11$ & $M$ & New Zealand & 27 & 1.86 \\
\hline $3 \mathrm{H}$ & $3 ; 9$ & $\mathrm{~F}$ & New Zealand & 0 & 0.31 & $6 \mathrm{~A}$ & $6 ; 0$ & M & Korea (17) & 30 & 2.27 \\
\hline 31 & $3 ; 9$ & M & New Zealand & 0 & 2.50 & $6 \mathrm{~B}$ & $6 ; 0$ & $\mathrm{~F}$ & Korea (67) & 55 & 2.72 \\
\hline 3J & $3 ; 11$ & M & New Zealand & 0 & 2.37 & 6C & $6 ; 1$ & M & New Zealand & 42 & 1.88 \\
\hline $3 \mathrm{~K}$ & $3 ; 11$ & M & New Zealand & 0 & 2.28 & $6 D$ & $6 ; 2$ & M & New Zealand & 42 & 1.67 \\
\hline $3 \mathrm{~L}$ & $3 ; 11$ & $\mathrm{~F}$ & New Zealand & 27 & 2.16 & $6 \mathrm{E}$ & $6 ; 3$ & M & New Zealand & 18 & 1.33 \\
\hline $4 \mathrm{~A}$ & $4 ; 0$ & M & New Zealand & 34 & 1.33 & $6 F$ & $6 ; 6$ & $\mathrm{~F}$ & Korea (14) & 36 & 0.79 \\
\hline $4 \mathrm{~B}$ & $4 ; 3$ & $\mathrm{~F}$ & Korea (7) & 7 & 4.83 & $6 \mathrm{G}$ & $6 ; 6$ & M & New Zealand & 36 & 1.71 \\
\hline $4 C$ & $4 ; 3$ & $\mathrm{~F}$ & New Zealand & 0 & 0.66 & $6 \mathrm{H}$ & $6 ; 6$ & $M$ & New Zealand & 36 & 2.03 \\
\hline $4 \mathrm{D}$ & $4 ; 7$ & M & Korea (9) & 9 & 3.15 & 61 & $6 ; 7$ & $\mathrm{~F}$ & New Zealand & 24 & 1.18 \\
\hline $4 \mathrm{E}$ & $4 ; 8$ & $\mathrm{~F}$ & Korea (35) & 46 & 5.05 & $6 \mathrm{~J}$ & $6 ; 9$ & M & New Zealand & 0 & 0.86 \\
\hline $4 \mathrm{~F}$ & $4 ; 8$ & $\mathrm{~F}$ & New Zealand & 12 & 1.77 & $6 K$ & $6 ; 9$ & $\mathrm{~F}$ & New Zealand & 5 & 1.38 \\
\hline $4 G$ & $4 ; 11$ & $M$ & New Zealand & 0 & 1.03 & $6 \mathrm{~L}$ & $6 ; 11$ & $\mathrm{~F}$ & Korea (18) & 30 & 1.51 \\
\hline $4 \mathrm{H}$ & $4 ; 11$ & M & New Zealand & 0 & 2.50 & $7 \mathrm{~A}$ & $7 ; 4$ & M & New Zealand & 0 & 0.70 \\
\hline $5 \mathrm{~A}$ & $5 ; 0$ & M & New Zealand & 39 & 2.03 & $7 \mathrm{~B}$ & $7 ; 4$ & $\mathrm{~F}$ & New Zealand & 0 & 1.35 \\
\hline $5 B$ & $5 ; 1$ & $\mathrm{~F}$ & Korea (34) & 38 & 1.19 & $7 C$ & $7 ; 6$ & $\mathrm{~F}$ & Korea (62) & 37 & 1.23 \\
\hline $5 C$ & $5 ; 1$ & $\mathrm{~F}$ & New Zealand & 0 & 1.80 & $7 D$ & $7 ; 6$ & M & New Zealand & 0 & 0.07 \\
\hline $5 D$ & $5 ; 1$ & $\mathrm{~F}$ & Korea (3) & 24 & 1.33 & $7 E$ & $7 ; 6$ & $\mathrm{~F}$ & New Zealand & 0 & 0.64 \\
\hline $5 E$ & $5 ; 3$ & $\mathrm{~F}$ & New Zealand & 0 & 0.70 & $7 F$ & $7 ; 9$ & $\mathrm{~F}$ & New Zealand & 0 & 2.27 \\
\hline $5 F$ & $5 ; 5$ & $\mathrm{~F}$ & New Zealand & 34 & 1.65 & $7 \mathrm{G}$ & $7 ; 11$ & $\mathrm{~F}$ & Korea (70) & 36 & 0.72 \\
\hline
\end{tabular}


conditions known to impact on speech/language development (e.g. hearing loss, craniofacial anomaly, autism spectrum disorder). In total, parents of 244 children were contacted about the study. Of those, parents of 20 children agreed to participate ( $8.2 \%$ of those contacted). An additional 32 children were recruited via chain-referral sampling, making up a total of 52 children. Table 4 illustrates age, gender, birth country and language exposure of the $52 \mathrm{KEB}$ children.

All children in the study were exposed to the Korean language from birth, regardless of where they were born. Age of English language exposure (in months) varied greatly (mean = 19.87 months; $\mathrm{SD}=18.76$ ). Of the 52 children in the study, 38 were born in New Zealand. Only 20 of these were exposed to the English language from birth. For those who were born in South Korea, the age of arrival in New Zealand (in months) is given in parentheses in Table 4. Following the procedure used in Goldstein, Bunta [67], the proportion of language exposure was calculated by the total hours of Korean language exposure divided by the total hours of English language exposure in a child's typical week. The mean proportion of language exposure of the sample was 2.06 ( $\mathrm{SD}=2.03)$, which indicates that the children, on average, were exposed to Korean language environments 2.06 times more than they were to English language environments. The proportion of language exposure shows a decreasing trend with age.

Eight of the 52 children had a father who was a monolingual English speaker and a Korean mother (3D, 3H, 4C, 5E, 5J, 7A, $7 \mathrm{D}$, and $7 \mathrm{E}$ ). These were among 12 children who were receiving greater input in English than in Korean. For all children, the primary source (i.e. the greatest amount of relative exposure) of Korean language exposure was the home environ- ment. Figure 1 illustrates the frequency of reported language mixing behaviours of the primary carers when they speak with their children at home. Secondary sources of Korean language exposure included weekend Korean language school $(\mathrm{n}=25)$, church $(\mathrm{n}=20)$, regular playgroup $(\mathrm{n}=17)$, private Korean language lessons $(n=9)$, private maths lessons $(n=3)$ and other extracurricular activities $(n=16)$. All children were attending an early education centre/kindergarten or school where English was the language of instruction. For 39 children, the primary source of English language exposure was school or kindergarten with the remaining 13 children exposed to the English language primarily at home. Other than home and school/kindergarten, bilingual children were exposed to the English language at church $(n=7)$, regular playgroup $(\mathrm{n}=8)$, private English language lessons $(\mathrm{n}=2)$ and other extracurricular activities $(\mathrm{n}=19)$.

The mean age of mothers at the time the child was born was 32.08 years $(\mathrm{SD}=3.76 ; \min =26 ; \max =43)$. On average, the mothers had 16.64 years of formal education $(\mathrm{SD}=2.22$; $\min =12$; $\max =25$ ) and fathers had 16.93 years of formal education ( $\mathrm{SD}=2.40$; $\min =12$; $\max =25$ ). The mean annual household income, estimated from the recent population census [68] was $\$ 91,631.77 \mathrm{NZD}(\mathrm{SD}=22,416.71$; $\min =42,400$; $\max =$ $133,500)$, which was higher than the national average household income of $\$ 85,588 \mathrm{NZD}$ [69]. The parents of 13 children (25.0\%) reported varying degrees of concerns about their children's language development. The majority of the concerns were directly related to bilingualism (e.g. knowing some words in one language but not in the other; limited opportunity to speak English). This is not unusual for bilingual children $[70,71]$.

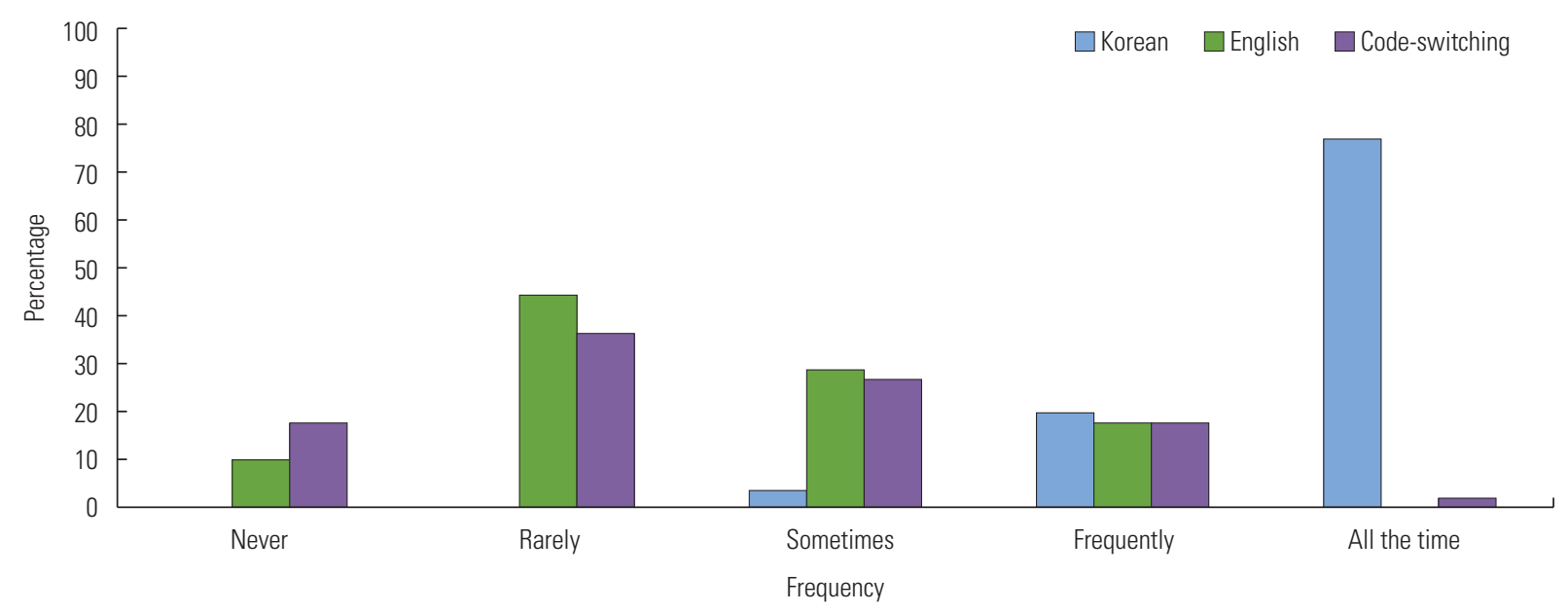

Figure 1. Reported language-mixing behaviours of the primary carers when speaking to their children. 


\section{Materials and data collection}

The Diagnostic Evaluation of Articulation and Phonology (DEAP) [72] and the Assessment of Phonology and Articulation for Children (APAC) [73] were used to obtain single word samples for English and Korean, respectively. The DEAP has separate Articulation and Phonology subtests. The APAC has a single list of words, among which phonemes in various word positions are specified for establishing the consonant inventory. For the efficiency of data presentation, the specified phonemes in the APAC will be referred to as the Articulation subtest and the whole list as the Phonology subtest. Both assessments were completed with all children by the first author. Children's responses were audio-recorded using a digital voice recorder.

\section{Phonetic transcription and data analysis}

The first author transcribed children's responses on-line and completed the phonetic transcriptions from the audio-recording for all children. Two independent transcribers with experience in phonetic transcription and working with children with SSD re-transcribed $10 \%$ of the data. The percentage of agreement with the phonetic transcriptions done by the first author was $95.0 \%$ for English and 96.4\% for Korean. The small number of disagreements in the phonetic transcriptions were discussed with other independent transcribers to determine the final transcriptions to be used for analysis.

The analyses were kept close the methods used in the monolingual normative studies in English [6] and in Korean [57]. Children's speech samples from the Articulation subtest of each assessment were independently analysed to establish phonetic inventories for each language. The Phonology subtest was used to obtain segmental accuracy, calculated by the PCC and PVC for each language. In addition, the PCC scores for each consonant class were also calculated from the Phonology subtests. Imitated responses were included in the analysis, as previous research suggests there is no significant difference between spontaneous and imitated productions $[74,75]$.

Inferential statistical analysis took into consideration the inherent sampling biases in studies of bilinguals in a country where they are a minority population [28]. Appropriate data treatments or distribution-free nonparametric statistical tests which do not make stringent assumptions about the underlying populations [76] were used wherever possible. A logarithmic transformation was performed on the PCC and PVC scores [77] and the transformed scores were entered into a multiple linear regression model to consider the factors influencing phonological development in bilingual children. The following variables were all initially considered as explanatory variables for the regression model; age (in months), gender, age of English language exposure (in months), the proportion of language exposure, the number of contexts in which the children were experiencing English and Korean language exposure, the estimated annual household income, years of mother's education and mother's age at the time of child's birth (in years). The number of contexts in which the children were exposed to English was removed to address collinearity in the model and was excluded from regression analyses. Using the backward elimination method, the contribution of all the other variables to the model was considered and, on the basis of F-statistics for testing each partial coefficient, the single variable contributing the least to the model was removed from the model (n.b. probability of F-to-remove $\geq 0.100$ as the removal criterion). The model was re-evaluated with the remaining variables. This process was repeated until the regression equation of best fit could be derived.

For comparison with monolingual children, the consonant inventories of individual children were compared against the age of acquisition of consonants from monolingual studies. The child's phonological development was considered decelerated if the speech sounds expected to be mastered by monolingual children of the same age group were not in the child's inventory. The child's phonological development was considered accelerated if the speech sounds expected to be mastered in an older age group by the monolingual standard were present in the KEB child's consonant inventory. To compare the PCC scores, KEB children who obtained a PCC score that fell one standard deviation below the normative age group mean were considered to be decelerated and those who scored above one standard deviation were considered to be accelerated in phonological development. Potential factors associated with acceleration and deceleration were also explored, using a descriptive comparison based on standard deviations and inferential statistics using Mann-Whitney $U$ and Chi-square $\left(\chi^{2}\right)$ tests. Lastly, transfer is only concerned with production of language-specific speech sounds in the other language, as framed within the IDS model [15].

\section{RESULTS}

\section{Segmental accuracy}

Table 5 summarises the mean PCC and PVC scores. The 
mean PCC and PVC scores show fluctuations in both languages from 3;0 to 7;11. While English vowel production reaches $100 \%$ by the age of seven years, the bilingual children still deleted the post-consonantal glide in Korean, which is not uncommon even for MK children. Nevertheless, all KEB children had complete vowel inventories in both languages. Compared to the ME study [6], the PVC scores of the younger KEB children are lower.

\section{Production of stops}

English and Korean stops were present in all KEB children. To be consistent with the MK normative study [57], syllable positions were considered for Korean stops. For $/ \mathrm{p} /$ and $/ \mathrm{t} /$, there was no evidence that these stops were mastered at different ages depending on syllable position. Four children (3A, 3G,

Table 5. Percentage of consonants correct (PPC) and percentage of vowels correct (PVC) (standard deviations in the parentheses)

\begin{tabular}{lccccc}
\hline \multirow{2}{*}{ Age } & \multicolumn{2}{c}{ PCC } & & \multicolumn{2}{c}{ PVC } \\
\cline { 6 - 6 } \cline { 5 - 6 } \cline { 5 - 6 } & English & Korean & & English & Korean \\
\hline $3 ; 0-3 ; 5$ & $64.39(13.76)$ & $77.75(9.39)$ & & $93.81(5.05)$ & $96.65(1.30)$ \\
$3 ; 6-3 ; 11$ & $75.58(10.89)$ & $85.45(5.06)$ & & $96.15(3.47)$ & $95.41(2.74)$ \\
$4 ; 0-4 ; 5$ & $72.33(21.09)$ & $79.78(10.17)$ & $97.00(1.80)$ & $95.87(0.73)$ \\
$4 ; 6-4 ; 11$ & $85.81(9.86)$ & $94.65(3.61)$ & & $97.69(2.29)$ & $97.80(1.02)$ \\
$5 ; 0-5 ; 5$ & $92.32(5.33)$ & $96.03(2.73)$ & & $99.36(0.70)$ & $98.16(1.85)$ \\
$5 ; 6-5 ; 11$ & $89.67(10.96)$ & $92.64(7.81)$ & & $99.63(0.63)$ & $98.95(1.79)$ \\
$6 ; 0-6 ; 5$ & $93.33(4.93)$ & $93.63(4.24)$ & & $97.44(2.56)$ & $98.05(2.81)$ \\
$6 ; 6-6 ; 11$ & $97.37(2.19)$ & $96.42(2.83)$ & & $99.63(0.63)$ & $99.30(0.96)$ \\
$7 ; 0-7 ; 5$ & $99.65(0.50)$ & $98.51(0.70)$ & & $100(0)$ & $97.56(1.72)$ \\
$7 ; 6-7 ; 11$ & $99.01(1.08)$ & $96.83(2.56)$ & & $100(0)$ & $98.54(1.34)$ \\
\hline
\end{tabular}

4B and 4D), however, produced / $\mathrm{k} /$ in syllable initial position but not in syllable final position. By the age of five years, the children produced all Korean stops in all syllable positions. Figure 2 shows the accuracy of stops in English and Korean. There is a trend for higher accuracy in English than in Korean in older age groups.

\section{Production of fricatives}

Production of fricatives was variable, especially for younger children and for English. In Korean, /s/ was produced by all KEB children expect for two children (3C and 3E) in the youngest age group. All KEB children aged five years or older had / $\mathrm{s}^{*} /$ in their consonant inventory. Only one or two children in each age group did not produce $/ \mathrm{s}^{*} /$ in the younger age groups. The children who produced $/ \mathrm{s}^{*} /$ also had $/ \mathrm{s} /$ in their inventory but not vice versa. The remaining Korean fricative, $/ \mathrm{h} /$, was present in the inventory of all children except for one child (4B). All English fricatives were present in all KEB children aged 6;7 and older, except for one child, 7C, who did not produce /3/. Given the variable nature of production of fricatives in younger children, we present the fricative inventory for individual children younger than 6;7 (Table 6). In general, /f, $\mathrm{v}, \mathrm{s}, \int, \mathrm{h} /$ were produced by the majority of threeyear-old KEB children, followed by $/ z, \theta$ / in older age groups. The last fricatives to be mastered in KEB children appear to be $/ \partial /$ and $/ 3 /$ at seven years.

Figure 3 illustrates production accuracy of fricatives for all children. There is a tendency for higher accuracy in Korean fricatives compared to English fricatives in the younger age groups. There is an opposite trend in the older age groups.

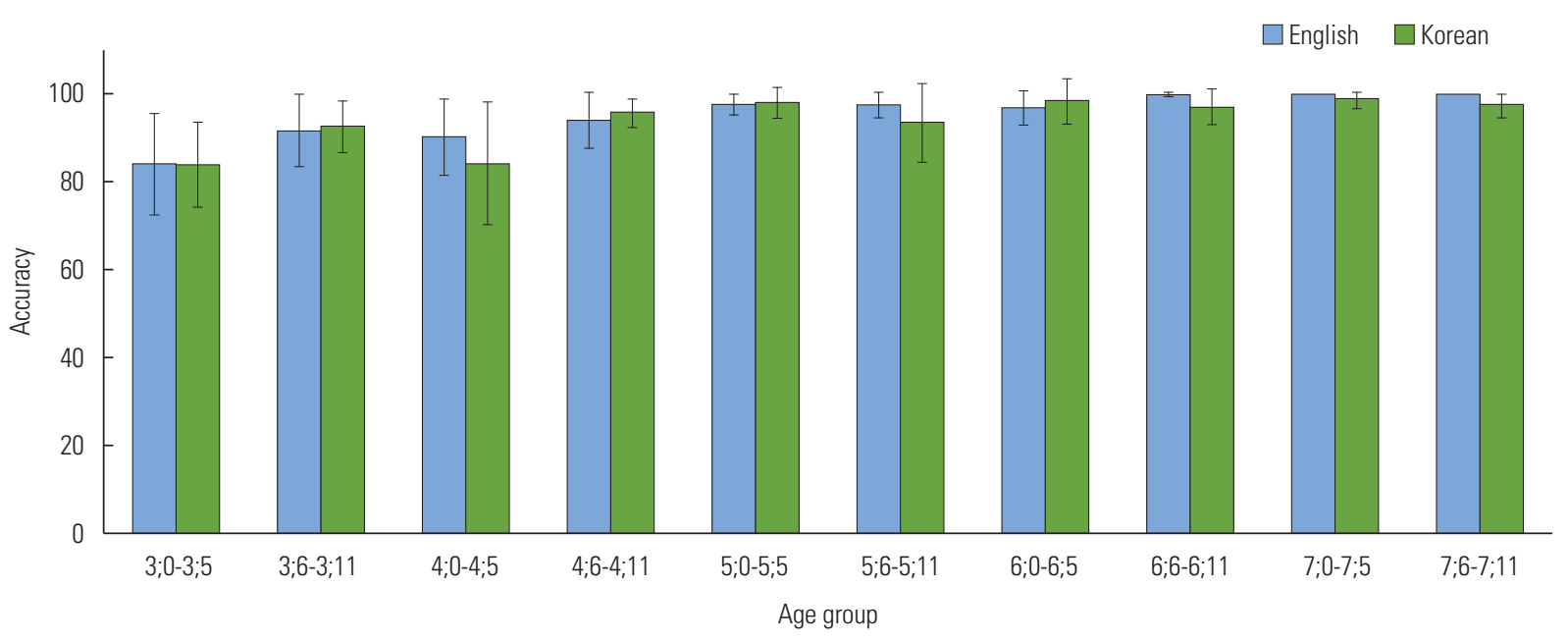

Figure 2. Production accuracy of stops (error bars represent standard deviations). 


\section{Production of affricates}

One child (4B) did not produce any English affricate consonants (but produced all Korean affricates). One child (3C) did not produce /ts*/ (Korean affricate) but produced all other affricates (in both Korean and English). The remaining children

Table 6. English fricative inventory of Korean-English bilingual children

\begin{tabular}{|c|c|c|c|}
\hline Participant & Inventory & Participant & Inventory \\
\hline $3 \mathrm{~A}$ & $\mathrm{f}, \mathrm{v}, \theta, \mathrm{s}, \mathrm{z}, \int, \mathrm{h}$ & $5 \mathrm{~A}$ & $\mathrm{f}, \mathrm{v}, \theta, ð, \mathrm{~s}, \mathrm{z}, \int, 3, \mathrm{~h}$ \\
\hline 3B & $\mathrm{f}, \mathrm{v}, \mathrm{s}, \mathrm{z}, \int, \mathrm{h}$ & $5 B$ & $\mathrm{f}, \mathrm{v}, \mathrm{s}, \mathrm{z}, \int, 3, \mathrm{~h}$ \\
\hline 3C & $\mathrm{v}, \mathrm{s}, \mathrm{z}, \int, \mathrm{h}$ & $5 C$ & $\mathrm{f}, \mathrm{v}, \mathrm{s}, \mathrm{z}, \int, \mathrm{h}$ \\
\hline $3 \mathrm{D}$ & $\mathrm{f}, \mathrm{v}, \theta, \mathrm{s}, \mathrm{z}, \int, \mathrm{h}$ & $5 \mathrm{D}$ & $\mathrm{f}, \mathrm{v}, \theta$, $, \mathrm{s}, \mathrm{z}, \int, 3, \mathrm{~h}$ \\
\hline $3 \mathrm{E}$ & $\mathrm{h}$ & $5 E$ & $\mathrm{f}, \mathrm{v}, \theta, \partial, \mathrm{s}, \mathrm{z}, \int, \mathrm{h}$ \\
\hline $3 F$ & $\mathrm{f}, \mathrm{v}, \theta, \mathrm{s}, \mathrm{z}, \int, 3, \mathrm{~h}$ & $5 F$ & $\mathrm{f}, \mathrm{v}, \theta$, $, \mathrm{s}, \mathrm{z}, \int, 3, \mathrm{~h}$ \\
\hline $3 \mathrm{G}$ & $\mathrm{s}, \int, \mathrm{h}$ & $5 \mathrm{G}$ & $\mathrm{f}, \mathrm{v}, \mathrm{s}, \mathrm{z}, \int, \mathrm{h}$ \\
\hline $3 \mathrm{H}$ & $\mathrm{f}, \mathrm{v}, \theta, \mathrm{s}, \mathrm{z}, \int, \mathrm{z}, \mathrm{h}$ & $5 \mathrm{H}$ & $\mathrm{f}, \mathrm{v}, \theta, \mathrm{s}, \mathrm{z}, \int, 3, \mathrm{~h}$ \\
\hline 31 & $\mathrm{f}, \mathrm{v}, \theta, \mathrm{s}, \mathrm{z}, \int, \mathrm{h}$ & 51 & $\mathrm{f}, \mathrm{v}, \theta, \partial, \mathrm{s}, \mathrm{z}, \int, \mathrm{h}$ \\
\hline $3 G$ & $\mathrm{f}, \mathrm{v}, \theta, \mathrm{s}, \int, \mathrm{h}$ & $5 \mathrm{~J}$ & 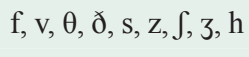 \\
\hline $3 \mathrm{~K}$ & $\mathrm{f}, \mathrm{v}, \mathrm{s}, \int, \mathrm{h}$ & $5 K$ & $\mathrm{f}, \mathrm{v}, \theta$, ठ, s, z, $, 3, \mathrm{~h}$ \\
\hline $3 \mathrm{~L}$ & $\mathrm{f}, \mathrm{v}, \mathrm{s}, \int, \mathrm{h}$ & $5 \mathrm{~L}$ & $\mathrm{f}, \mathrm{v}, \mathrm{z}, \int, 3, \mathrm{~h}$ \\
\hline $4 \mathrm{~A}$ & $\mathrm{f}, \theta, \mathrm{v}, \mathrm{s}, \mathrm{z}, \int, \mathrm{h}$ & $5 M$ & 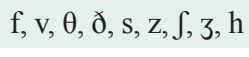 \\
\hline 4B & $\theta, \mathrm{h}$ & $6 \mathrm{~A}$ & 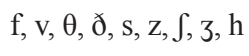 \\
\hline $4 C$ & $\mathrm{f}, \mathrm{v}, \theta, \mathrm{s}, \mathrm{z}, \int, \mathrm{h}$ & $6 B$ & $\mathrm{f}, \mathrm{v}, \theta, \mathrm{s}, \mathrm{z}, \int, \mathrm{h}$ \\
\hline $4 \mathrm{D}$ & $\mathrm{f}, \mathrm{v}, \theta, \mathrm{s}, \int, \mathrm{h}$ & $6 C$ & $\mathrm{f}, \mathrm{v}, \theta, \mathrm{s}, \mathrm{z}, \int, \mathrm{h}$ \\
\hline $4 \mathrm{E}$ & $\mathrm{f}, \mathrm{v}, \mathrm{s}, \mathrm{z}, \int, \mathrm{h}$ & $6 \mathrm{D}$ & $\mathrm{f}, \mathrm{v}, \theta, \mathrm{s}, \mathrm{z}, \int, 3, \mathrm{~h}$ \\
\hline $4 F$ & $\mathrm{f}, \mathrm{v}, \mathrm{\partial}, \mathrm{s}, \mathrm{z}, \int, \mathrm{h}$ & $6 \mathrm{E}$ & $\mathrm{f}, \mathrm{v}, \theta$, , $, \mathrm{s}, \mathrm{z}, \int, \zeta, \mathrm{h}$ \\
\hline $4 G$ & $\mathrm{f}, \mathrm{v}, \theta, \partial, \mathrm{s}, \mathrm{z}, \int, \mathrm{z}, \mathrm{h}$ & $6 F$ & $\mathrm{f}, \mathrm{v}, \theta, \partial, \mathrm{s}, \mathrm{z}, \int, \mathrm{h}$ \\
\hline \multirow[t]{2}{*}{$4 \mathrm{H}$} & $\mathrm{f}, \mathrm{v}, \mathrm{s}, \mathrm{z}, \int, \mathrm{h}$ & $6 \mathrm{G}$ & $\mathrm{f}, \mathrm{v}, \theta, \partial, \mathrm{s}, \mathrm{z}, \int, \mathrm{h}$ \\
\hline & & $6 \mathrm{H}$ & $\mathrm{f}, \mathrm{v}, \mathrm{s}, \mathrm{z}, \int, \mathrm{h}$ \\
\hline
\end{tabular}

produced all affricates in both languages. Younger KEB children were more accurate in producing Korean affricates than English affricates (Figure 4). By the age of five years, the gap in accuracy between English and Korean affricates narrowed.

\section{Production of nasals}

All nasals were present in the consonant inventories of KEB children except for one child (3E), who did not produce $/ \mathrm{y} /$ in Korean but did produce it in English. Contrary to the findings from MK children [57], all KEB children produced $/ \mathrm{m} /$ and /n/ in both syllable initial and final positions. Nasals were produced with relatively high accuracy from a young age. English nasals were produced more accurately than Korean nasals across the age groups. By five, the English nasals reached 100\% but KEB children produced sporadic errors in their production of Korean nasals even at the age of seven years (Figure 5).

\section{Production of liquids}

English /1/ was produced by all KEB children except for one child (3L). The English rhotic consonant was produced by some younger children but it is not until after 5;6, when the majority of KEB produced / $\mathrm{I} /$. To be consistent with the MK normative study, we specified syllable positions for the Korean liquid. All KEB children produced /1/ in syllable final position. The majority of the youngest age group did not produce /1/ in syllable initial position (only 3C produced /l/ in syllable initial position). In the older age groups, most children produced /l/ in syllable initial position with the exception of $3 \mathrm{H}, 4 \mathrm{~B}, 4 \mathrm{C}$ and $4 \mathrm{H}$. Three children $(4 \mathrm{H}, 6 \mathrm{H}$ and $6 \mathrm{~L})$ produced /l/ in syllable initial position but produced it as [l] not as its correct allophonic variant, $[r]$. Production accuracy

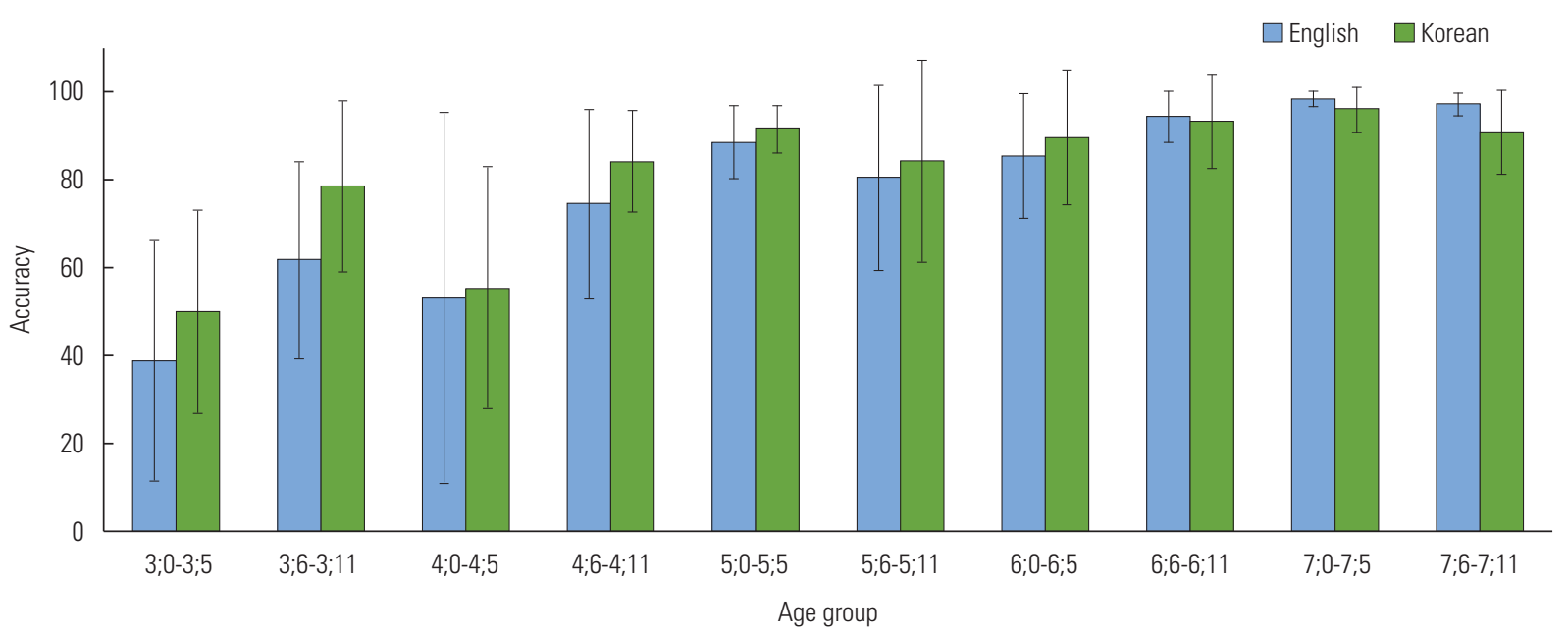

Figure 3. Production accuracy of fricatives (error bars represent standard deviations). 


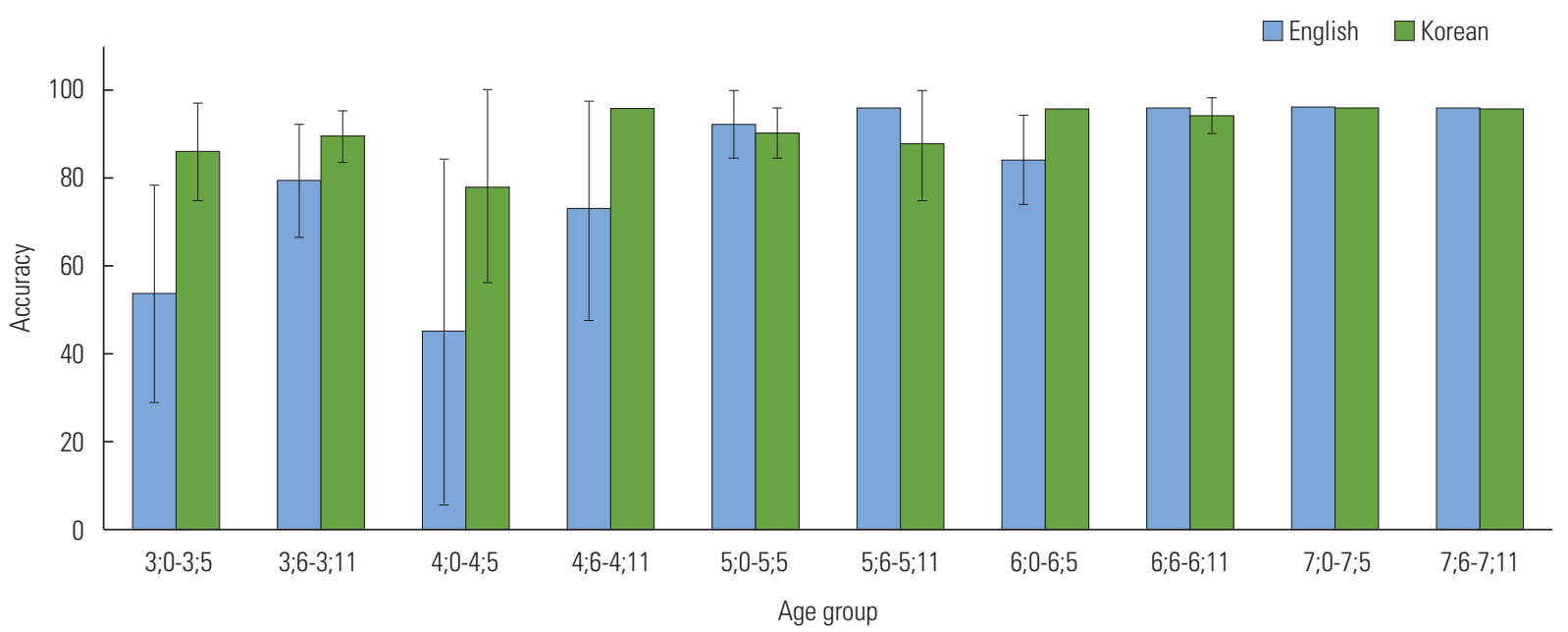

Figure 4. Production accuracy of affricates (error bars represent standard deviations).

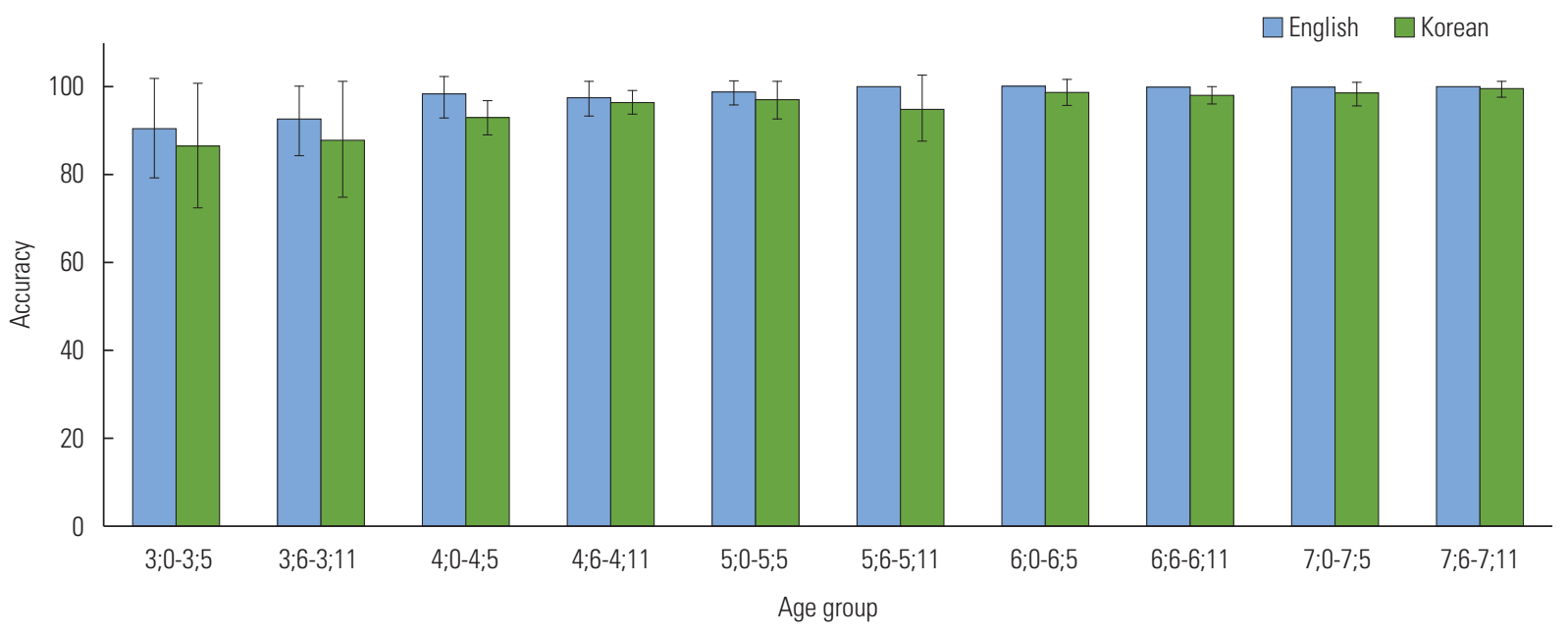

Figure 5. Production accuracy of nasals (error bars represent standard deviations).

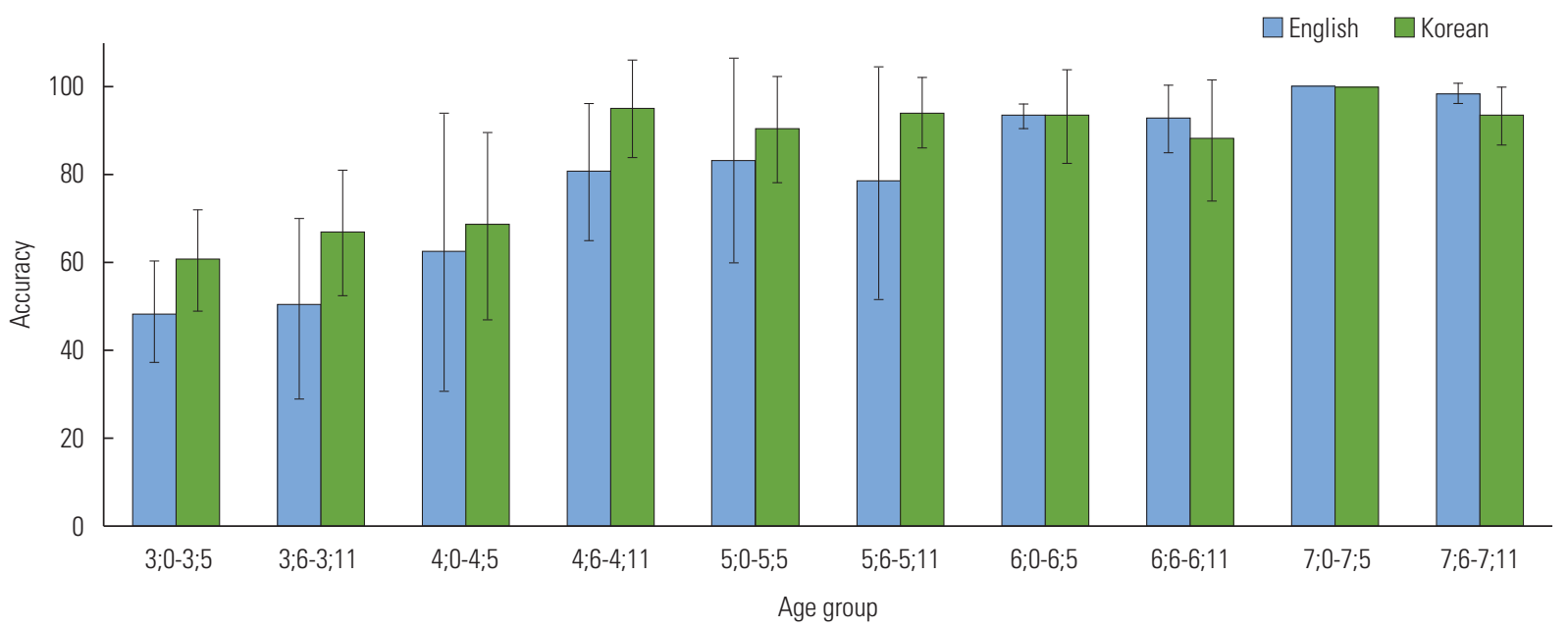

Figure 6. Production accuracy of liquids (error bars represent standard deviations). 
of liquids in each language is shown in Figure 6. There is a trend for higher accuracy of the Korean liquid in younger age groups but higher accuracy of English liquids in older age groups.

\section{Production of glides}

Only English glides are reported. All KEB children produced /w/, and only by the age of six years did all KEB children produced $/ \mathrm{j} /$. In age groups younger than $6 ; 0$, there were eight children (3A, 3D, 3H, 3K, 3L, 4C, 5B and 5L) who did not produce $/ \mathrm{j} /$, which is reflected in the production accuracy of glides in Figure 7.

\section{Factors influencing phonological development}

The results from the regression analyses are summarised in Table 7 . Age was consistently identified as a statistically significant factor for segmental accuracy in both languages. The number of different Korean language environments to which children were exposed accounted for the variance in Korean PCC scores ( $p=0.007)$ and the age of first English language exposure accounted for the variance in Korean PVC scores $(p=0.004)$. Nevertheless, our regression models could only accounted for approximately $50 \%$ of the variance in the PCC scores and much less of the variance in the PVC scores in both languages.

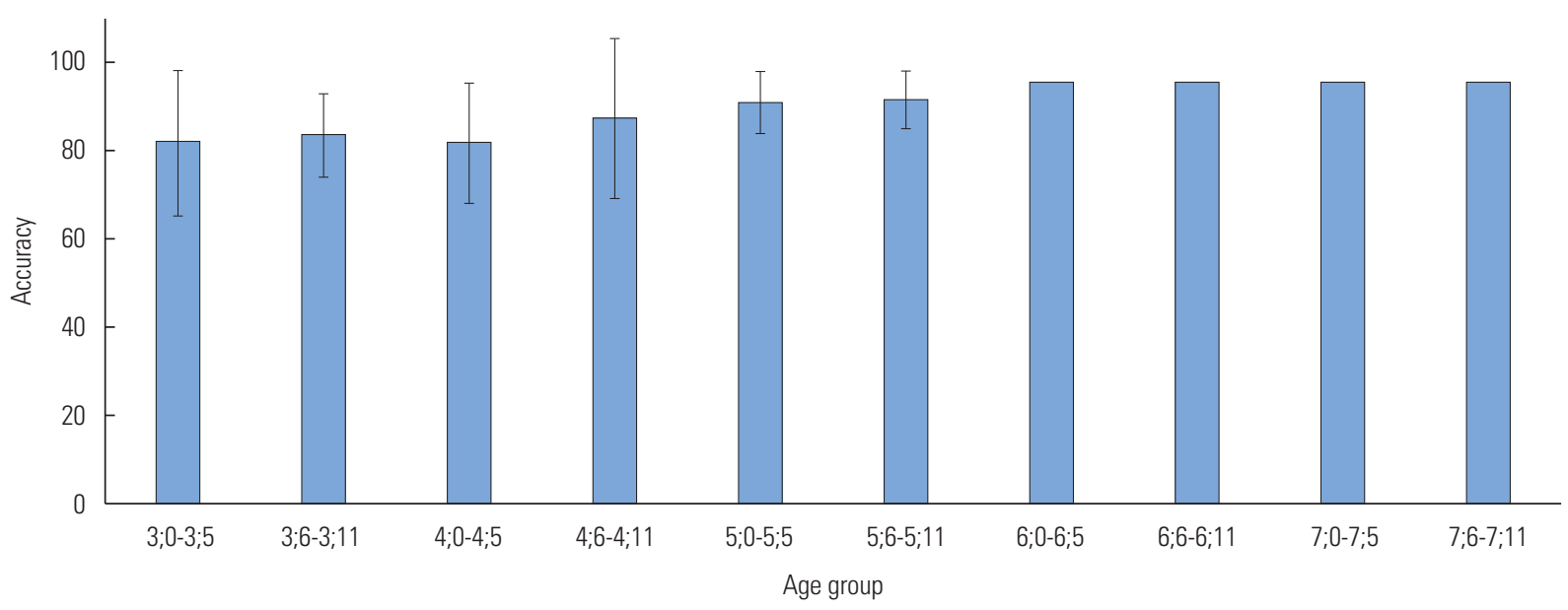

Figure 7. Production accuracy of glides (error bars represent standard deviations).

Table 7. Multiple linear regression results

\begin{tabular}{|c|c|c|c|c|c|c|c|c|c|c|c|c|c|}
\hline & \multicolumn{4}{|c|}{ Model and ANOVA } & \multirow[b]{2}{*}{$p$} & & \multicolumn{2}{|c|}{$\begin{array}{c}\text { Unstandardised } \\
\text { coefficients }\end{array}$} & \multirow{2}{*}{$\begin{array}{c}\begin{array}{c}\text { Standardised } \\
\text { coefficients }\end{array} \\
\text { Beta }\end{array}$} & \multirow[b]{2}{*}{$\mathrm{t}$} & \multirow[b]{2}{*}{$p$} & \multicolumn{2}{|c|}{$\begin{array}{l}95 \% \text { Confidence } \\
\text { interval for B }\end{array}$} \\
\hline & $\mathrm{R}^{2}$ & $\begin{array}{c}\text { Adjusted } \\
\mathrm{R}^{2}\end{array}$ & SE & $F$ & & & B & SE & & & & $\begin{array}{l}\text { Lower } \\
\text { bound }\end{array}$ & $\begin{array}{l}\text { Upper } \\
\text { bound }\end{array}$ \\
\hline \multirow[t]{3}{*}{ English PCC } & 0.527 & 0.507 & 0.059 & 26.195 & $<0.001$ & Constant & 1.650 & 0.046 & & 35.962 & $<0.001$ & 1.558 & 1.743 \\
\hline & & & & & & Age & 0.003 & $<0.001$ & 0.691 & 6.868 & $<0.001$ & 0.002 & 0.004 \\
\hline & & & & & & Income & $<0.001$ & $<0.001$ & 0.117 & 1.757 & 0.085 & $<0.001$ & $<0.001$ \\
\hline \multirow[t]{3}{*}{ English PVC } & 0.394 & 0.369 & 0.011 & 15.305 & $<0.001$ & Constant & 1.963 & 0.006 & & 316.242 & $<0.001$ & 1.951 & 1.976 \\
\hline & & & & & & Age & $<0.001$ & $<0.001$ & 0.600 & 4.334 & $<0.001$ & $<0.001$ & 0.001 \\
\hline & & & & & & EngEx & $<0.001$ & $<0.001$ & -0.219 & -1.930 & 0.060 & $<0.001$ & $<0.001$ \\
\hline \multirow[t]{3}{*}{ Korean PCC } & 0.498 & 0.476 & 0.032 & 23.281 & $<0.001$ & Constant & 1.827 & 0.020 & & 91.145 & $<0.001$ & 1.786 & 1.867 \\
\hline & & & & & & Age & 0.002 & $<0.001$ & 0.635 & 6.144 & $<0.001$ & 0.001 & 0.002 \\
\hline & & & & & & KorNum & 0.008 & 0.003 & 0.292 & 2.819 & 0.007 & 0.002 & 0.015 \\
\hline \multirow[t]{3}{*}{ Korean PVC } & 0.349 & 0.322 & 0.008 & 12.626 & $<0.001$ & Constant & 1.971 & 0.004 & & 441.974 & $<0.001$ & 1.962 & 1.980 \\
\hline & & & & & & Age & $<0.001$ & $<0.001$ & 0.449 & 3.813 & $<0.001$ & $<0.001$ & $<0.001$ \\
\hline & & & & & & EngEx & $<0.001$ & $<0.001$ & 0.362 & 3.073 & 0.004 & $<0.001$ & $<0.001$ \\
\hline
\end{tabular}




\section{Comparison with monolingual children}

The consonant inventories were compared against the age of acquisition of consonants of the respective monolingual studies (Table 8). For the majority of the children, whether the bi- lingual children's phonological skills were accelerated or decelerated could not be clearly determined. For example, $3 \mathrm{E}$ did not have /f/ or $/ \mathrm{v} /$ in his consonant inventory, suggesting deceleration, but $/ \mathrm{t} \mathrm{f} /$ and $/ \mathrm{d}_{3} /$ were present in the inventory,

Table 8. Consonant inventories of Korean-English bilingual children in comparison to monolingual children

\begin{tabular}{|c|c|c|c|c|c|c|c|c|}
\hline & \multicolumn{2}{|c|}{ English } & \multicolumn{2}{|l|}{ Korean } & & \multicolumn{2}{|c|}{ English } & \multirow{2}{*}{$\begin{array}{c}\text { Korean } \\
\text { Accelerated Decelerated }\end{array}$} \\
\hline & Accelerated & Decelerated & Accelerated & Decelerated & & Accelerated & Decelerated & \\
\hline $3 \mathrm{~A}$ & $\theta, \int, \mathrm{t} \int, \mathrm{d}_{3}$ & $\mathrm{j}$ & $\begin{array}{l}\mathrm{p}, \mathrm{t}, \mathrm{t}^{\mathrm{h}}, \mathrm{k}, \mathrm{k}^{*}, \mathrm{k}^{\mathrm{h}}, \mathrm{s}, \mathrm{s}^{*} \\
\mathrm{ts}, \mathrm{ts}^{*}, \mathrm{ts}^{\mathrm{h}}, \mathrm{n}, \mathrm{m}, \mathrm{l}, \mathrm{y}\end{array}$ & & $5 G$ & & 3 & $\mathrm{~s}, \mathrm{~s}^{*}$ \\
\hline 3B & $\int, \mathrm{t} \int, \mathrm{d} 3$ & & $\begin{array}{l}\mathrm{p}, \mathrm{t}, \mathrm{t}^{\mathrm{h}}, \mathrm{k}, \mathrm{k}^{*}, \mathrm{k}^{\mathrm{h}}, \mathrm{s}, \mathrm{ts} \\
\mathrm{ts}^{*}, \mathrm{ts}^{\mathrm{h}}, \mathrm{n}, \mathrm{m}, \mathrm{l}, \mathrm{\eta}\end{array}$ & & $5 \mathrm{H}$ & $\theta, \mathrm{I}$ & & $\mathrm{s}, \mathrm{s}^{*}$ \\
\hline $3 C$ & $\int, \mathrm{t} \int, \mathrm{d}_{3}, \mathrm{I}$ & $\mathrm{f}$ & $\begin{array}{l}\mathrm{p}, \mathrm{t}, \mathrm{t}^{\mathrm{h}}, \mathrm{k}, \mathrm{k}^{*}, \mathrm{k}^{\mathrm{h}}, \mathrm{ts}, \mathrm{ts}^{\mathrm{h}}, \\
\mathrm{n}, \mathrm{m}, \mathrm{l}, \mathrm{\eta}\end{array}$ & & 51 & $\theta$, б & 3 & $\mathrm{~s}, \mathrm{~s}^{*}$ \\
\hline 3D & $\theta, \int, \mathrm{t} \int, \mathrm{d} 3, \mathrm{I}$ & $\mathrm{j}$ & $\begin{array}{l}\mathrm{p}, \mathrm{t}, \mathrm{t}^{\mathrm{h}}, \mathrm{k}, \mathrm{k}^{*}, \mathrm{k}^{\mathrm{h}}, \mathrm{s}, \mathrm{s}^{*} \\
\mathrm{ts}, \mathrm{ts} \mathrm{s}^{*}, \mathrm{ts}^{\mathrm{h}}, \mathrm{n}, \mathrm{m}, \mathrm{l}, \mathrm{\eta}\end{array}$ & & $5 \mathrm{~J}$ & $\theta$, ठ, $\mathrm{I}$ & & $\mathrm{s}, \mathrm{s}^{*}$ \\
\hline $3 \mathrm{E}$ & $\mathrm{t} \int, \mathrm{d} 3, \mathrm{I}$ & $\mathrm{f}, \mathrm{v}, \mathrm{s}, \mathrm{z}$ & $\begin{array}{l}\mathrm{p}, \mathrm{t}, \mathrm{t}^{\mathrm{h}}, \mathrm{k}, \mathrm{k}^{*}, \mathrm{k}^{\mathrm{h}}, \mathrm{ts}, \\
\mathrm{ts}^{*}, \mathrm{ts}^{\mathrm{h}}, \mathrm{n}, \mathrm{m}, \mathrm{l}\end{array}$ & & $5 K$ & $\theta$, ठ, $\mathrm{I}$ & & $\mathrm{s}, \mathrm{s}^{*}$ \\
\hline $3 F$ & $\theta, \int, 3, d_{3}$ & & $\begin{array}{l}\mathrm{t}, \mathrm{k}, \mathrm{k}^{\mathrm{h}}, \mathrm{s}, \mathrm{s}^{*}, \mathrm{ts}, \mathrm{ts} \mathrm{s}^{*} \\
\mathrm{ts}^{\mathrm{h}}, \mathrm{n}, \mathrm{m}, \mathrm{y}\end{array}$ & & $5 \mathrm{~L}$ & I & $\mathrm{s}, \mathrm{j}$ & $\mathrm{s}, \mathrm{s}^{*}$ \\
\hline $3 G$ & $\int, d_{3}$ & $f, v, z$ & $\begin{array}{l}\mathrm{t}, \mathrm{k}, \mathrm{k}^{\mathrm{h}}, \mathrm{s}, \mathrm{ts}, \mathrm{ts}^{*}, \mathrm{ts}^{\mathrm{h}}, \mathrm{n}, \\
\mathrm{m}, \mathrm{y}\end{array}$ & & $5 \mathrm{M}$ & $\theta, \partial, \mathrm{I}$ & & $\mathrm{s}, \mathrm{s}^{*}$ \\
\hline $3 \mathrm{H}$ & $\theta, \int, 3, d_{3}$ & $\mathrm{j}$ & $\begin{array}{l}\mathrm{t}, \mathrm{k}, \mathrm{k}^{\mathrm{h}}, \mathrm{s}, \mathrm{s}^{*}, \mathrm{ts}, \mathrm{ts} * \\
\mathrm{ts}^{\mathrm{h}}, \mathrm{n}, \mathrm{m}, \mathrm{y}\end{array}$ & & $6 \mathrm{~A}$ & $\theta$, б & & $\mathrm{s}, \mathrm{s}^{*}$ \\
\hline 31 & $\theta, \int, d_{3}$ & & $\begin{array}{l}\mathrm{t}, \mathrm{k}, \mathrm{k}^{\mathrm{h}}, \mathrm{s}, \mathrm{s}^{*}, \mathrm{ts}, \mathrm{ts} * \\
\mathrm{ts}^{\mathrm{h}}, \mathrm{n}, \mathrm{m}, \mathrm{y}\end{array}$ & & $6 \mathrm{~B}$ & $\theta$ & 3, I & $\mathrm{s}, \mathrm{s}^{*}$ \\
\hline $3 \mathrm{G}$ & $\theta, \int, d_{3}$ & $\mathrm{z}$ & $\begin{array}{l}\mathrm{t}, \mathrm{k}, \mathrm{k}^{\mathrm{h}}, \mathrm{s}, \mathrm{s}^{*}, \mathrm{ts}, \mathrm{ts} * \\
\mathrm{ts}^{\mathrm{h}}, \mathrm{n}, \mathrm{m}, \mathrm{y}\end{array}$ & & $6 C$ & $\theta$ & 3 & $\mathrm{~s}, \mathrm{~s}^{*}$ \\
\hline $3 \mathrm{~K}$ & $\int, d_{3}, \mathrm{I}$ & $\mathrm{z}, \mathrm{j}$ & $\begin{array}{l}\mathrm{t}, \mathrm{k}, \mathrm{k}^{\mathrm{h}}, \mathrm{s}, \mathrm{s}^{*}, \mathrm{ts}, \mathrm{ts} \mathrm{s}^{*} \\
\mathrm{ts}^{\mathrm{h}}, \mathrm{n}, \mathrm{m}, \mathrm{y}\end{array}$ & & $6 \mathrm{D}$ & $\theta$ & & $\mathrm{s}, \mathrm{s}^{*}$ \\
\hline $3 \mathrm{~L}$ & $\int, d_{3}$ & $\mathrm{z}, \mathrm{l}, \mathrm{j}$ & $\begin{array}{l}\mathrm{t}, \mathrm{k}, \mathrm{k}^{\mathrm{h}}, \mathrm{s}, \mathrm{s}^{*}, \mathrm{ts}, \mathrm{ts}^{*}, \\
\mathrm{ts}^{\mathrm{h}}, \mathrm{n}, \mathrm{m}, \mathrm{y}\end{array}$ & & $6 \mathrm{E}$ & & & $\mathrm{s}, \mathrm{s}^{*}$ \\
\hline $4 \mathrm{~A}$ & $\int$ & 3 & $\mathrm{k}^{\mathrm{h}}, \mathrm{s}, \mathrm{y}$ & & $6 F$ & $\theta$, б & 3 & $\mathrm{~s}, \mathrm{~s}^{*}$ \\
\hline $4 \mathrm{~B}$ & $\theta$ & $\begin{array}{l}\mathrm{f}, \mathrm{v}, \mathrm{s}, \mathrm{z}, \mathrm{z} \\
\mathrm{t} \int, \mathrm{d} 3\end{array}$ & $\mathrm{k}^{\mathrm{h}}, \mathrm{s}, \mathrm{y}$ & h & $6 G$ & $\theta$, ð & 3 & $\mathrm{~s}, \mathrm{~s}^{*}$ \\
\hline $4 C$ & $\theta, \int$ & $3, \mathrm{j}$ & $\mathrm{k}^{\mathrm{h}}, \mathrm{s}, \mathrm{s}^{*}, \mathrm{y}$ & & $6 \mathrm{H}$ & & 3 & $\mathrm{~s}, \mathrm{~s}^{*}$ \\
\hline $4 \mathrm{D}$ & $\theta, \int$ & 3 & $\mathrm{~s}, \mathrm{~s}^{*}$ & & 61 & $\theta$, б & & $\mathrm{s}, \mathrm{s}^{*}$ \\
\hline $4 \mathrm{E}$ & $\int, \mathrm{I}$ & 3 & $\mathrm{~s}, \mathrm{~s}^{*}$ & & 6J & $\theta$, б & & $\mathrm{s}, \mathrm{s}^{*}$ \\
\hline $4 F$ & ð, $\int$ & 3 & $\mathrm{~s}, \mathrm{~s}^{*}$ & & $6 K$ & $\theta$, б & & $\mathrm{s}, \mathrm{s}^{*}$ \\
\hline $4 \mathrm{G}$ & $\theta, \partial, \int, \mathrm{I}$ & & $\mathrm{s}, \mathrm{s}^{*}$ & & $6 \mathrm{~L}$ & $\theta$, б & & $\mathrm{s}, \mathrm{s}^{*}$ \\
\hline $4 \mathrm{H}$ & $\int, \mathrm{I}$ & 3 & $\mathrm{~s}$ & & $7 \mathrm{~A}$ & & & \\
\hline $5 \mathrm{~A}$ & $\theta$, ठ, I & & $\mathrm{s}, \mathrm{s}^{*}$ & & $7 \mathrm{~B}$ & & & \\
\hline $5 B$ & & $\mathrm{j}$ & $\mathrm{s}, \mathrm{s}^{*}$ & & $7 C$ & & 3 & \\
\hline $5 C$ & & 3 & $\mathrm{~s}, \mathrm{~s}^{*}$ & & $7 D$ & & & \\
\hline $5 D$ & $\theta$, ठ & & $\mathrm{s}, \mathrm{s}^{*}$ & & $7 \mathrm{E}$ & & & \\
\hline $5 \mathrm{E}$ & $\mathrm{I}$ & 3 & $\mathrm{~s}, \mathrm{~s}^{*}$ & & $7 F$ & & & \\
\hline $5 F$ & $\theta, \partial, \mathrm{I}$ & & $\mathrm{s}, \mathrm{s}^{*}$ & & $7 G$ & & & \\
\hline
\end{tabular}


suggesting acceleration. In Korean, acceleration was evident in all children younger than seven years. Deceleration in the consonant inventory was observed only in one child.

The PCC scores of the current study were compared to the previous monolingual studies in Figures 8 and 9. In younger age groups, there is a trend for higher PCC scores in monolingual children compared to the bilingual children in both languages. The PCC scores of KEB children older than these ages could not be compared because Dodd, Holm [6] and Kim and Pae [57] included ME and MK children up to the ages of 6;11 and 6;5, respectively.

When the PCC scores of the bilingual children were compared against the ME normative data, $28.89 \%$ of the bilingual children obtained a PCC score that was one standard deviation below the age group means provided in Dodd et al. [6].

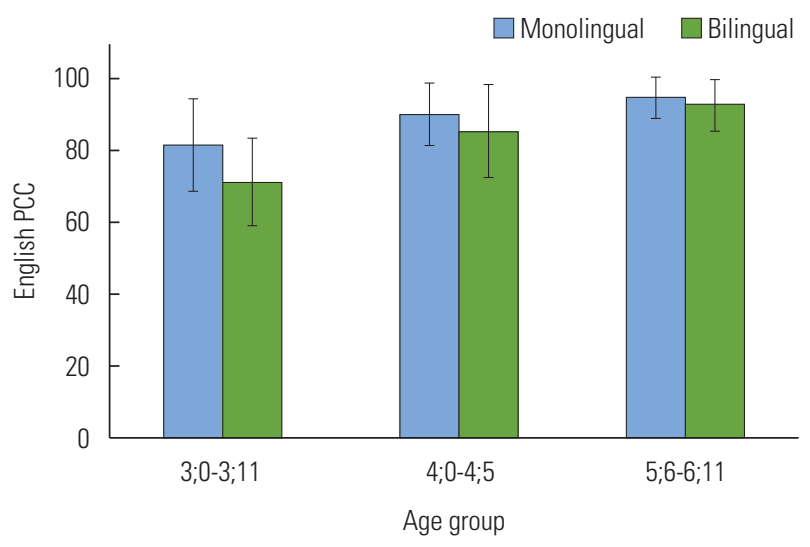

Figure 8. Comparison of percentage of consonants correct (PCC) between monolingual English-speaking children and the bilingual children of the current study (error bars show standard deviations).
No one obtained a PCC score one standard deviation above the mean of the ME normative data. When compared against the MK normative data, $18.42 \%$ of the bilingual children aged between 3;0 and 6;5 obtained a PCC score one standard deviation below the age group means provided in Kim and Pae [57]. No child scored one standard deviation above the MK normative mean. Of the children who scored one standard deviation below the monolingual means in either language, $42.86 \%$ scored one standard deviation below the monolingual means in both languages, $50.00 \%$ scored one standard deviation below the monolingual means only in English and 7.14\% only in Korean. The percentage of children who obtained a PCC score that is one standard deviation below the monolingual means for each age group is illustrated in Figure 10.

The characteristics of the children who obtained a PCC score one standard deviation below and those that scored within one standard deviation of the monolingual normative means were compared using Mann-Whitney U and Chisquare tests. The results are summarised in Table 9. There was no gender difference in the findings for English $\left(\chi^{2}(1, \mathrm{~N}=\right.$ $45)=1.171, p=0.337)$ or for Korean $\left(\chi^{2}(1, \mathrm{~N}=38)=0.175, p=\right.$ 1.000). In English, the KEB children whose PCC scores were one standard deviation below the ME age group means were statistically significantly younger ( mean $=52.46, \mathrm{SD}=13.72$ ) than those who scored within one standard deviation ( $m e a n=63.34, \mathrm{SD}=12.97$ ). The KEB children whose PCC scores were one standard deviation below the ME age group means (mean $=3.67, \mathrm{SD}=3.33$ ) were also exposed to proportionally less English than those who scored within one standard deviation (mean $=1.64, \mathrm{SD}=0.92)$. The two groups also

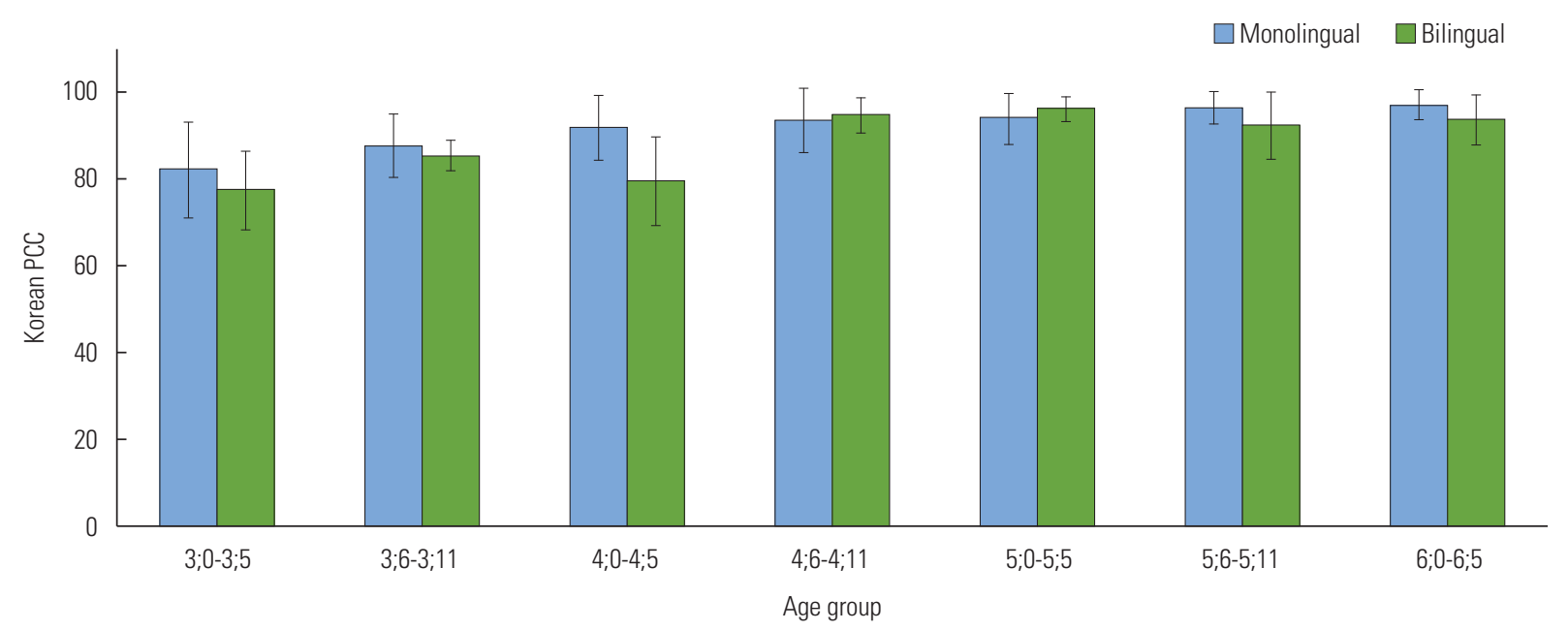

Figure 9. Comparison of percentage of consonants correct (PCC) between monolingual Korean-speaking children and the bilingual children of the current study (error bars show standard deviations). 


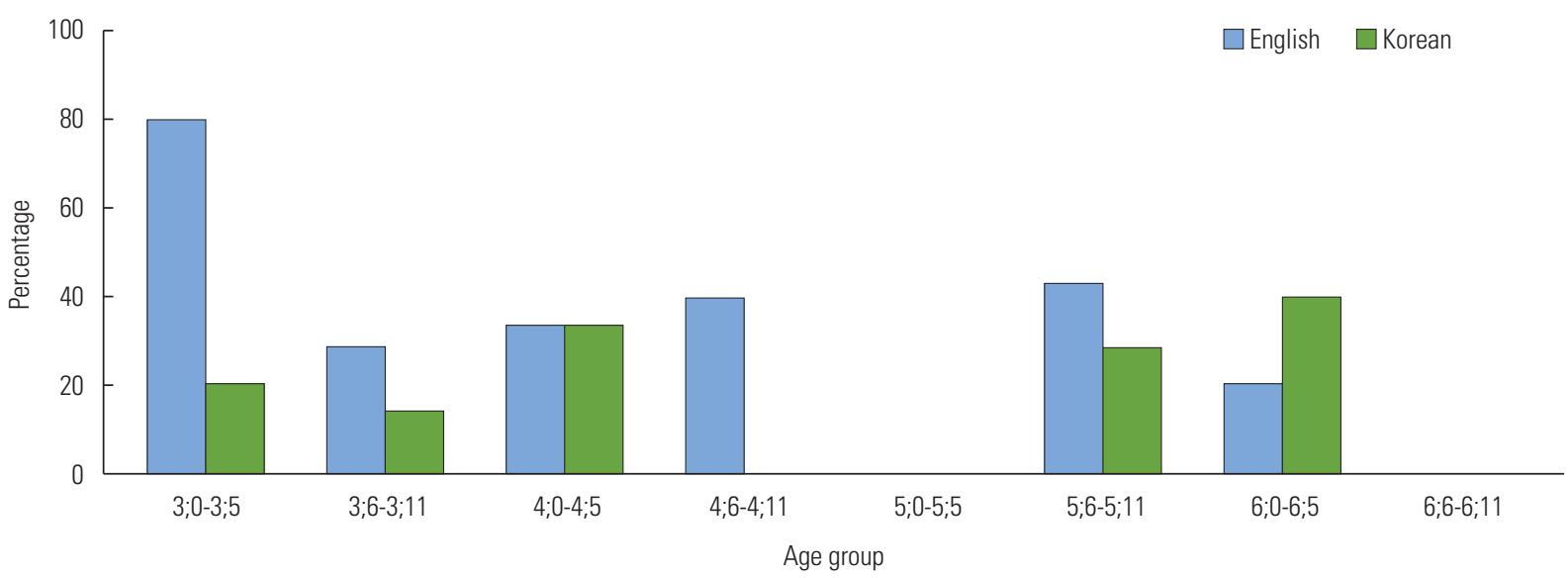

Figure 10. Percentage of children who obtained a percentage of consonants correct (PCC) score one standard deviation below the monolingual age group means.

Table 9. Comparison of the characteristics between the Korean-English bilingual children whose percentage of consonants correct was one standard deviation below and within one standard deviation of the age group means of monolingual normative studies

\begin{tabular}{|c|c|c|c|c|c|c|}
\hline \multirow{2}{*}{ Mann-Whitney } & \multicolumn{3}{|c|}{ English } & \multicolumn{3}{|c|}{ Korean } \\
\hline & $\mathrm{U}$ & $p$ & $r$ & $\mathrm{U}$ & $p$ & $r$ \\
\hline Age & 114.00 & 0.018 & -0.351 & 82.00 & 0.318 & -0.162 \\
\hline Age of first English exposure & 191.50 & 0.673 & -0.063 & 61.00 & 0.066 & -0.347 \\
\hline Proportion of language exposure & 108.00 & 0.012 & -0.373 & 99.50 & 0.735 & -0.055 \\
\hline Number of contexts for English & 128.00 & 0.033 & -0.117 & 68.00 & 0.105 & -0.263 \\
\hline Number of contexts for Korean & 177.50 & 0.433 & -0.318 & 53.00 & 0.032 & -0.347 \\
\hline Mother's age & 183.00 & 0.531 & -0.093 & 96.50 & 0.651 & -0.073 \\
\hline Mother's education & 171.50 & 0.515 & -0.099 & 97.50 & 0.867 & -0.028 \\
\hline Annual household income & 197.00 & 0.780 & -0.043 & 97.00 & 0.660 & -0.071 \\
\hline
\end{tabular}

differed in the number of contexts in which they were receiving English language exposure. Those who scored within the ME normative age group means tended to be exposed to a greater number of English language environments (mean = $2.25, \mathrm{SD}=1.107$ ) than those who scored one standard deviation below the ME norms ( mean $=1.54, \mathrm{SD}=0.660$ ).

In Korean, the two groups differed only in the number of contexts in which they were receiving Korean language exposure. The KEB children who scored within the MK age group means tended to be exposed to a greater number of Korean language environments $($ mean $=3.13, \mathrm{SD}=1.586)$ than those who scored one standard deviation below the MK norms (mean $=1.71, \mathrm{SD}=1.113$ ).

\section{Transfer}

There were two children ( $4 \mathrm{~A}$ and $6 \mathrm{E}$ ) who substituted $[\theta]$ for /s/ or $/ \mathrm{s}^{*}$ / in Korean (five occurrences for each child), which can be taken as evidence of transfer of an English-specific speech sound (interdental fricative) in the production of Korean words. These two children were siblings. Both were male, born in New Zealand and Korean-language dominant (as revealed by the proportion of language exposure). Evidence of Korean-language specific consonants produced in English words was also found. Eleven children (21.2\%) substituted Korean affricate consonants for English affricate consonants (e.g. [wots ${ }^{\mathrm{h}}$ ] for $/$ wot $\mathrm{f} /$ ). Such substitutions were observed only sporadically for most children. There were no unifying characteristics of these children who produced the Korean-specific consonants in English.

\section{DISCUSSION}

\section{Characteristics of Korean-English bilingual children's phonological skills}

The age of completion of the consonant inventory in the KEB children was comparable to monolingual children in both 
languages. However, the trajectories towards the completion of the inventories were different from the monolingual children in both languages. The majority of KEB children produced all Korean consonants by the age of four years with the exception of $/ \mathrm{s}^{*} /$ (and /l/ in syllable initial position). As a general trend, $/ \mathrm{s}^{*} /$ appeared to be mastered after 4;6. Although all children produced [l], its allophonic variant, $[r]$, appeared to be mastered after 4;6. In English, all stops, affricates, nasals, /l/ and /w/ appeared to be mastered before 3;6. Unlike Korean, no three-year-old child had a complete consonant inventory in English. The youngest child to have a complete English consonant inventory was 4G (aged 4;11). Age of mastery of $/ \mathrm{x} /$ and $/ \mathrm{j} /$ appeared to be after $5 ; 6$ and $5 ; 0$, respectively. English fricatives could be categorised into early-, middleand late-developing groups. Early-developing fricatives were /f, v, s, $\int, \mathrm{h} /$, middle-developing fricatives were $/ \mathrm{z}, \theta /$ and the late group included $/ \delta, 3 /$.

The PPC scores were higher in Korean than in English in younger age groups, whereas the opposite trend was observed in older age groups. English stops and nasals reached $100 \%$ accuracy but KEB children continued to produce errors in Korean stops and nasals at the age of seven years. Lower accuracy of the Korean fricatives and liquid in older age groups also contributed to this trend. The English PCC scores in younger age groups were particularly low, which can be attributed to low accuracy of fricatives, affricates and liquids. Errors in English fricative consonants were particularly high. The PVC scores were generally higher in English than in Korean, except for the youngest age group. The trend for lower PVC scores in Korean can be attributed to the post-consonantal glide deletion in Korean across the age groups.

We also investigated potential factors influencing phonological development in KEB children. Chronological age was the most influential factor, which is consistent with a previous cross-sectional study in Cantonese-English bilingual children with a similar sample size [34]. Age of English exposure was also a statistically significant factor predicting PVC scores in Korean. Most vowel errors in Korean were associated with diphthongs. Although the deletion of glides was treated as an error in the PVC calculation, post-consonantal glide deletion is often observed in natural speech in Korean [54]. This stringent PVC calculation method which treated the post-consonantal glide deletion as an error was used in the current study, because it was suspected that such deletion might be less likely in KEB children. That is, the influence of the phonemic status of glides in English on the Korean phonology might lower the chance of post-consonantal glide deletion in the production of Korean words. This was not the case, as such deletion was observed regardless of age and language exposure. The regression results suggested that the higher PVC scores in Korean were associated with later exposure to the English language. Nevertheless, the impact of the age of the English language exposure, along with the child's age, was marginal on the PVC scores in Korean. As far as segmental accuracy is concerned (both PCC and PVC), the age of English language exposure was not a deterministic factor. Our findings are in agreement with most previous empirical studies such as Holm and Dodd [34].

We found that the number of different contexts in which the children were receiving language input influenced their phonological skills. Greater number of different Korean language contexts was associated with higher Korean PCC scores. This finding is consistent with previous studies examining the properties of language input in bilingual children's language development [78-80]. Caution must be exercised, however, when interpreting the regression results of the current study, due to a small sample size in such a heterogeneous population. More than half of the variance of the segmental accuracy in the KEB children in the study was not accounted for by the regression model. For example, age, according to the regression model, predicts the PCC scores, with older age associated with higher PCC scores. However, the English PCC scores of 3D, 3E and 5G were $81.02 \%, 43.26 \%$, and $78.72 \%$, respectively. It is easy to see how "the older the child, the more accurate their production" may be a statement of overgeneralisation.

\section{Acceleration or deceleration?}

Deceleration was not the norm in the current study, as suggested previously $[19,20]$. The majority of the KEB children obtained PCC scores that would be expected in monolingual children. We found no evidence that older bilingual children show advanced phonological skills compared to monolingual children of the same age, as tentatively alluded to in Hambly, Wren [28]. Almost half of the children aged between 5;6 and 6;5 obtained PCC scores that were considerably lower than monolingual children (Figure 10). Moreover, there was no evidence of acceleration in KEB children in terms of their segmental accuracy in either language. The PCC scores of bilingual children may become comparable to that of monolingual children beyond the age of six years but older bilingual children are not necessarily more accurate than age-matched monolingual children. 
KEB children whose Korean PCC scores were lower than the MK age group means tended to be exposed to fewer Korean language contexts than those who scored comparably with the MK children. Children with English PCC scores that were lower than ME age group means were associated with younger age, less exposure to English and fewer English language contexts. These findings also appear to support the suggestion that the number of different language contexts to which the KEB children are exposed influences their segmental accuracy.

Segmental accuracy results of the current study therefore support deceleration, but not acceleration, as predicted by the IDS model. Note that deceleration in the IDS model was defined in quantitative terms ("overall progress") but acceleration in qualitative terms ("a certain property") [18]. However, the KEB children whose PCC scores were comparable with their monolingual counterparts do not easily fit within the framework of the IDS model. Such children have also been reported in previous studies [24,25]. Fabiano-Smith and Goldstein [15] claimed that the rates of phonological development in bilingual children can be similar to that in monolingual children because the acceleration and deceleration effects operate simultaneously, thereby cancelling out the effects of each other. However, acceleration and deceleration describe how the differences between monolingual and bilingual phonological development could be manifested rather than 'effects' that have certain operational reality [16-18,23]. There is no empirical evidence to suggest that acceleration and deceleration are operations that drive phonological development. As such, the ad hoc hypothesis made in Fabiano-Smith and Goldstein [15] is difficult to accept as an explanation for the findings of comparable segmental accuracy between monolingual and bilingual children. Furthermore, even those who obtained PCC scores comparable to monolingual children were qualitatively different from their monolingual counterparts as revealed by their consonant inventories (Table 8). Although there was no evidence of acceleration in segmental accuracy, acceleration was evident in the consonant inventories of most bilingual children. The previous studies that employed segmental accuracy measures $[21,38]$ also suggested that bilingual children were decelerated in their phonological skills, while the studies that compared consonant inventories suggested that bilingual and monolingual children had comparable phonological skills [23]. KEB children's consonant inventories could not be determined to be either accelerated or decelerated (Table 8). However, the outcomes of comparison between bilingual and monolingual children differ depending on whether quantitative (i.e. segmental accuracy) or qualitative measures (i.e. phonetic inventory) are used.

\section{Cross-linguistic effects}

The current study focused on the manifestation of cross-linguistic effects at points of structural overlap between Korean and English. At points of structural overlap, we found equivocal evidence that cross-linguistic effects were manifested, as suggested by Hulk and Müller [41] and Nicoladis and Paradis [40]. With regard to Korean /1/, structural overlap would hypothesise that KEB children are likely to produce [l] for [r], because of the influence of the English structural pattern in which English /1/ is realised as [1] [40]. However, only three KEB children produced [1] when they should have produced [r]. There does not seem to be a unique profile of these three children, which makes it unlikely that external factors are associated with erroneous productions of [1]. The influence of English structural pattern of /l/ on the production of Korean /l/ was not a common finding. In addition, the general trend in older KEB children for lower production accuracy of stops in Korean than in English can be attributed to KEB children aspirating word final stops. Korean stops are always lax, unreleased and unaspirated in word final position. According to structural overlap, we would expect the Korean pattern to influence KEB children to unrelease and deaspirate word final stops in English. The opposite was observed. However, word final voiced obstruents in English were produced as their voiceless counterparts (e.g. [f.nk] for /fung/). Word final stops are always voiceless and voiced and voiceless lax stops are in complementary distribution in Korean, which likely influenced KEB children to erroneously produce voiceless word final stops in English. Interestingly, aspiration of word final stops in Korean and devoicing of word final obstruents in English were more frequent in younger children than older children. In addition, lower English PVC in younger children mostly reflected errors associated with tense-lax vowel distinction. For example, KEB children produced [i] for /I/ and vice versa. In other bilingual children who are exposed to two vowel systems in which one language makes phonemic tenselax vowel distinction and the other does not, errors associated with tense-lax vowel distinction have been documented [35]. However, unlike the previous study which found such errors even at the age of five years, lax-tense vowel distinction errors were found almost exclusively in the three-year-old KEB children in the current study. Younger KEB children were exposed 
to Korean proportionately more than they were to English (Table 4). In another example, English /s/ is realised as [s], while Korean /s/ is realised as either $[\mathrm{s}]$ or $\left[\mathrm{s}^{\mathrm{j}}\right]$, creating a structural overlap. Consistent with the previous findings [33], the age of mastery of /s/ in Korean is considerably earlier in KEB children compared to MK children. This could be interpreted as exposure to English facilitating acquisition of /s/ in Korean. There was a clear directionality in this case; from English to Korean. External factors did not seem to influence this, as almost all KEB children were accelerated in production of Korean /s/. Nevertheless, there were some difficulties in applying the core concepts of structural overlap to explaining the mastery of the Korean allophonic variant, $\left[\mathrm{s}^{\mathrm{j}}\right]$. Structural overlap would hypothesis that mastering this allophonic variant should be delayed, because English /s/ will influence KEB children to use its consistent pattern. This was not the case for KEB children. It could be that the presence of English phoneme, / $/$ / whose acoustic characteristics share perceptual similarity with Korean $\left[\mathrm{s}^{\mathrm{j}}\right]$, has negated the hypothesised delay in mastering the production of the allophonic variant of Korean /s/, providing only ambiguous evidence for structural overlap. An alternative explanation may be that earlier acquisition of /s/ in Korean is due to the transfer from English. As discussed earlier, Gildersleeve-Neumann and Wright [35] is one of the rare exceptions that found evidence for transfer. They found transfer from the dominant language (Russian) to the other language (English). In the current study, however, the majority of the KEB children were Korean dominant.

Transfer is worth further discussion. Although the evidence for transfer was scarce in previous literature, we found evidence for transfer as framed within the IDS model. However, there are some questions regarding the nature of transfer. The two children who produced $[\theta]$ for /s/ in Korean appear to support the hypothesised manifestation in the IDS model, as $/ \theta /$ is a phoneme specific to English. However, such a pattern of erroneous productions is a common developmental error pattern in MK children [81]. Hence, the substitution of [ $\theta$ ] for /s/ in Korean could reflect the developmental characteristic in bilingual phonological development [22]. The other noteworthy finding related to transfer was the substitution of [ $\left.\mathrm{ts}^{\mathrm{h}}\right]$ for $/ \mathrm{t} f /$ in English (e.g. [wats ${ }^{\mathrm{h}}$ ] for /wat $\mathrm{f} /$ ). This finding may need to be interpreted in the context of phonological development in KEB children. Age of mastery of Korean /s/ coincided with that of English /s/. In addition, English $/ \mathrm{f} /$ appeared to be mastered at the same time as $/ \mathrm{s} /$. English $/ \mathrm{J} /$ shares perceptual similarity with the palatalised allophonic variant of
Korean /s/. Thus, the mastery of /s/ (including its allophonic variant) in Korean corresponded with the mastery of these segments in English (i.e. phonemes). These findings may also be related to age of acquisition of affricate consonants. The age of acquisition of affricate consonants in KEB children is unexpectedly early in both languages. It is earlier than that reported in respective monolingual children. It may be that earlier mastery of $/ \mathrm{s} /$ in English and /s/ in Korean had a 'knockon' effect, leading to early mastery of affricates in both languages. It should also be noted that the English affricate consonants were not mastered by the three and four year olds in the previous KEB studies [33, 42]. These studies only included English language learners. The majority of the three and four year olds in the current study were exposed to both languages from birth. However, even $3 \mathrm{G}$ and $4 \mathrm{E}$, who were exposed to English language environments for the duration of two and ten months, respectively, had the English affricates in their consonant inventory. The difference between the current study and the previous studies may be attributed to the difference in methodology. Anderson [33] required at least two occurrences of the phone for it to be included in the inventories.

Although KEB children had /s/, / $/$ and / $\mathrm{t} /$ in their English consonant inventory, they were not always produced accurately (see Figures 3 and 4). For example, some children produced $\left[\int\right]$ for $/ \mathrm{s} /$ (e.g. [ $[\mathrm{p} \mathrm{p} / \mathrm{Id} z]$ for $/ \operatorname{spsid} 3 /$ ) and $[\mathrm{s}]$ for $/ \mathrm{f} /($ e.g. [fisin] for $/ \mathrm{fr} \int \mathrm{In} /$ ) as well as $\left[\mathrm{ts}^{\mathrm{h}}\right.$ ] for $/ \mathrm{t} \mathrm{f} /$. In the current study, producing [ $\mathrm{f}]$ for $/ \mathrm{s} /$ and $[\mathrm{s}]$ for $/ \mathrm{S} /$ in English were not considered transfer, as we were investigating transfer as framed within the IDS model, which only considers production of language-specific speech sounds in the production of the other language. When we consider the allophonic variations of Korean /s/ and erroneous productions of $/ \mathrm{s} /, / \mathrm{s} /$ and $/ \mathrm{t} \mathrm{f} / \mathrm{in}$ English, these may reflect reorganisations of phonological systems in bilingual phonological development [32,35,39]. Bilingual children undergo a period during which phonemes and their realisation rules are being learned and re-specified for each language and this period may be characterised by overgeneralisation of realisation rules specific to one language to production of the other language, affecting the efficiency of extracting and following language-specific realisation rules $[32,35,82]$. Such reorganisation of phonological systems may be prominently manifested where there are shared segments or the points of structural overlap between two phonological systems [35,41], wherein the dynamic processes of specifying the phonemic contrasts and allophonic variations for each language take place $[32,35,39,43,83]$. Then, to suggest that 
producing $\left[\mathrm{ts}^{\mathrm{h}}\right]$ for $/ \mathrm{t} \mathrm{t} /$ in KEB children reflects a languagespecific phoneme being 'transferred' to the other language seems too simplistic.

\section{Limitations}

The current study has two limitations that should be noted. One obvious limitation is the small sample size. Only with a sufficiently large sample of KEB children, we can provide valuable KEB-specific normative data essential for accurately identifying KEB children with SSD. As mentioned, interpreting our statistical analyses require caution due to the small sample size. Moreover, the current study did not include approximately equal number of children in each age group. For example, only three children between the ages of 4;0 and 4;5 were recruited in the current study. This is likely the reason why the PCC scores for that age group deviates from what would be expected in developmental trend (see Table 5). We experienced challenges in participant recruitment during the data collection which lasted for about 20 months and the recruitment challenges have been discussed elsewhere [70].

Large-scale cross-sectional studies are undeniably useful in describing the developmental trends of KEB children as a population. As a recent study pointed out [84], however, crosssectional studies, such as the current study, can only provide a probabilistic statement about children's development and, especially for bilingual children who are heterogeneous, cross-sectional design may fail to capture within-subject variations during the course of development. For studies about the typically developing children to be useful for identifying children with developmental disorders, they need to report directly on the phenomenon of development, for which a longitudinal design is more appropriate. As such, the future research should consider both cross-section and longitudinal studies to generate the knowledge that is clinically useful for identifying SSD in KEB children.

\section{CONCLUSION}

At present, one of the most significant challenges faced by SLPs is the lack of information about typical phonological development in bilingual children [13]. Information about typical development is essential in identifying atypical development [6]. The current study reaffirms that there are inherent risks in applying monolingual norms for bilingual children with a suspected SSD. Therefore, clinical use of available monolingual norms should be avoided for bilingual children.
Along with the recently published studies in KEB children' error productions $[43,84]$, the findings of the current study provide a starting point for SLPs to consider typicality of phonological development in Korean-English bilingual children who are referred to the clinical services for suspected SSD.

We suggested that bilingual phonological development is characterised by both developmental processes and crosslinguistic effects [22]. Cross-linguistic effects reflect manifestations of interdependence between two differentiated phonological systems. Establishing two differentiated but interdependent phonological systems means that for the shared phonemes, if their realisation rules are different for each language, the phonological systems need to be reorganised to specify and refine language-specific realisation rules [32,35]. Although the current study does not offer unequivocal evidence for structural overlap, our findings suggest that crosslinguistic effects are likely to be manifested at points of overlap in allophonic variants between the two languages [15]. Identifying such points of overlap may be useful for SLPs to consider the potentially problematic areas for bilingual children.

\section{REFERENCES}

1. Law J, Boyle J, Harris F, Harkness A, Nye C. Prevalence and natural history of primary speech and language delay: Findings from a systematic review of the literature. International Journal of Language \& Communication Disorders. 2000;35(2):165-188.

2. Broomfield J, Dodd B. Children with speech and language disability: Caseload characteristics. International Journal of Language \& Communication Disorders. 2004;39(3):303-324.

3. Jessup B, Ward E, Cahill L, Keating D. Prevalence of speech and/ or language impairment in preparatory students in Northern Tasmania. International Journal of Speech-Language Pathology. 2008;10(5):364-377.

4. Flipsen P, Jr, Bankson NW, Bernthal JE. Classification and comorbidity in speech sound disorders. In: Bernthal JE, Bankson NW, Flipsen P, Jr, editors. Articulation and phonological disorders: Speech sound disorders in children. 7th ed. Boston, MA: Pearson Education; 2013. p. 114-143.

5. Shriberg LD. Developmental phonological disorders. In: Hixon TJ, Shriberg LD, Saxman JS, editors. Introduction to communicative disorders. Englewood Cliffs, NJ: Prentice Hall; 1980. p. 262-309.

6. Dodd B, Holm A, Zhu H, Crosbie S. Phonological development: A normative study of British English-speaking children. Clinical Linguistics \& Phonetics. 2003;17(8):671-643.

7. Bankson NW, Bernthal JE, Flipsen P, Jr. Speech sound assessment procedures. In: Bernthal JE, Bankson NW, Flipsen P, Jr, editors. Articulation and phonological disorders: Speech sound disorders in children. 7th ed. Boston, MA: Pearson Education; 2013. p. 180-211. 
8. McLeod S. Speech sound acquisition. In: Bernthal JE, Bankson NW, Flipsen P, Jr, editors. Articulation and phonological disorders: Speech sound disorders in children. 7th ed. Boston, MA: Pearson Education; 2013. p. 58-113.

9. Shriberg LD, Austin D, Lewis BA, McSweeny JL, Wilson DL. The percentage of consonants correct (PCC) metric: extensions and reliability data. Journal of Speech, Language, and Hearing Research. 1997;40:708-722.

10. Shriberg LD, Kwiatkowski J. Phonological disorders III: A procedure for assessing severity of involvement. Journal of Speech and Hearing Disorders. 1982;47:256-270.

11. Roseberry-McKibbin CA, Brice AE, O'Hanlon L. Serving English language learners in public school settings: A national survey. Language, Speech, and Hearing Services in Schools. 2005;36(1): 48-61.

12. Kritikos EP. Speech-language pathologists' beliefs about language assessment of bilingual/bicultural individuals. American Journal of Speech-Language Pathology. 2003;12(1):73-91.

13. Williams CJ, McLeod S. Speech-language pathologists' assessment and intervention practices with multilingual children. International Journal of Speech-Language Pathology. 2012;14(3):292305.

14. Guiberson M, Atkins J. Speech-language pathologists' preparation, practices, and perspectives on serving culturally and linguistically diverse children. Communication Disorders Quarterly. 2012;33(3):169-180.

15. Fabiano-Smith L, Goldstein BA. Phonological acquisition in bilingual Spanish-English speaking children. Journal of Speech, Language, and Hearing Research. 2010;53:160-178.

16. Prezas RF, Hodson BW, Schommer-Aikins M. Phonological assessment and analysis of bilingual preschoolers' Spanish and English word productions. American Journal of Speech-Language Pathology. 2014;23:176-185.

17. Keshavarz MH, Ingram D. The early phonological development of a Farsi-English bilingual child. International Journal of Bilingualism. 2002;6(3):255-269.

18. Paradis J, Genesee F. Syntactic acquisition in bilingual children: Autonomous or interdependent? Studies in Second Language Acquisition. 1996;18:1-25.

19. So LKH, Leung CSS. Phonological development of CantonesePutonghua bilingual children. In: Zhu H, Dodd B, editors. Phonological development and disorders in children: A multilingual perspective. Clevedon, UK: Multilingual Matters; 2006. p. 413-428.

20. Goldstein BA, Gildersleeve-Neumann C. Typical phonological acquisition in bilinguals. Perspectives on Communication Disorders and Sciences in Culturally and Linguistically Diverse Populations. 2007;14(2):11-16.

21. Bunta F, Fabiano-Smith L, Goldstein B, Ingram D. Phonological whole-word measures in 3-year-old bilingual children and their age-matched monolingual peers. Clinical Linguistics \& Phonetics. 2009;23(2):156-175.

22. Gildersleeve-Neumann CE, Kester ES, Davis BL, Peña ED. English speech sound development in preschool-aged children from bilingual English-Spanish environments. Language, Speech, and
Hearing Services in Schools. 2008;39(3):314-328.

23. Fabiano-Smith L, Barlow JA. Interaction in bilingual phonological acquisition: Evidence from phonetic inventories. International Journal of Bilingual Education and Bilingualism. 2010;13(1):81-97.

24. Goldstein BA, Fabiano L, Washington PS. Phonological skills in predominantly English-speaking, predominantly Spanish-speaking, and Spanish-English bilingual children. Language, Speech, and Hearing Services in Schools. 2005;36(3):201-218.

25. Lin L-C, Johnson CJ. Phonological patterns in Mandarin-English bilingual children. Clinical Linguistics \& Phonetics. 2010;24(45):369-386.

26. Law NCW, So LKH. The relationship of phonological development and language dominance in Bilingual Cantonese-Putonghua children. International Journal of Bilingualism. 2006;10(4): 405-428.

27. Grech H, Dodd B. Phonological acquisition in Malta: A bilingual language learning context. International Journal of Bilingualism. 2008;12(3):155-171.

28. Hambly H, Wren Y, McLeod S, Roulstone S. The influence of bilingualism on speech production: A systematic review. International Journal of Language \& Communication Disorders. 2013;48(1):124.

29. Major RC. Transfer in second language phonology: A review. In: Hansen Edwards JG, Zampini ML, editors. Phonology and second language acquisition. Amsterdam, The Netherlands: John Benjamins; 2008. p. 63-94.

30. MacWhinney B. A unified model of language acquisition. In: Kroll JF, de Groot AMB, editors. Handbook of bilingualism: Psycholinguistic approaches. New York, NY: Oxford University Press; 2005. p. 49-67.

31. Brice AE, Carson CK, Dennis O'Brien J. Spanish-English articulation and phonology of 4- and 5-year-old preschool children. Communication Disorders Quarterly. 2009;31(1):3-14.

32. Holm A, Dodd B. A longitudinal study of the phonological development of two Cantonese-English bilingual children. Applied Psycholinguistics. 1999;20:349-376.

33. Anderson RT. Phonological acquisition in preschoolers learning a second language via immersion: a longitudinal study. Clinical Linguistics \& Phonetics. 2004;18(3):183-210.

34. Holm A, Dodd B. Phonological development and disorders in bilingual children acquiring Cantonese and English. In: Zhu H, Dodd B, editors. Phonological development and disorders in children: A multilingual perspective. Clevedon, UK: Multilingual Matters; 2006. p. 286-325.

35. Gildersleeve-Neumann CE, Wright KL. English speech acquisition in 3- to 5-year-old children learning Russian and English. Language, Speech, and Hearing Services in Schools. 2010;41:429444.

36. Paradis J. Do bilingual two-year-olds have separate phonological systems? International Journal of Bilingualism. 2001;5(1):19-38.

37. Sorace A, Serratrice L. Internal and external interfaces in bilingual language development: Beyond structural overlap. International Journal of Bilingualism. 2009;13(2):195-210.

38. Gildersleeve-Neumann CE, Peña ED, Davis BL, Kester ES. Effects 
on L1 during early acquisition of L2: Speech changes in Spanish at first English contact. Bilingualism: Language and Cognition. 2009;12(2):259-272.

39. Dodd B, So LKH, Li W. Symptoms of disorder without impairment: The written and spoken errors of bilinguals. In: Dodd B, Campbell R, Worrall L, editors. Evaluating theories of language: Evidence from disordered communication. London, UK: Whurr; 1996. p. 119-136.

40. Nicoladis E, Paradis J. Learning to liaise and elide comme il faut: Evidence from bilingual children. Journal of Child Language. 2011;38(4):701-730.

41. Hulk A, Müller N. Bilingual first language acquisition at the interface between syntax and pragmatics. Bilingualism: Language and Cognition. 2000;3(3):227-244.

42. Ha S, Johnson CJ, Keuhn DP. Characteristics of Korean phonology: Review, tutorial, and case studies of Korean children speaking English. Journal of Communication Disorders. 2009;42:163-179.

43. Kim J-H, Ballard E, McCann CM. Error analysis of Korean-English bilingual children's speech productions. Clinical Archives of Communication Disorders. 2016;1(1):11-29.

44. Ahn S-C. Korean phonology. Yeon J, Song JJ, editors. London, UK: Saffron Books; 2009.

45. Cho T, Jun S-A, Ladefoged P. Acoustic and aerodynamic correlates of Korean stops and fricatives. Journal of Phonetics. 2002;30:193228.

46. Lee I, Ramsey SR. The Korean language. Albany, NY: State University of New York Press; 2000.

47. Kim H. The place of articulation of the Korean plain affricate in intervocalic position: An articulatory and acoustic study. Journal of the International Phonetic Association. 2001;31(2):229-257.

48. Kim H. The place of articulation of Korean affricates revisited. Journal of East Asian Linguistics. 1999;8:313-347.

49. Kim H, Honda K, Maeda S. Stroboscopic-cine MRI study of the phasing between the tongue and the larynx in the Korean threeway phonation contrast. Journal of Phonetics. 2005;33(1):1-26.

50. Ladefoged P, Johnson K. A course in phonetics. 6th ed. Boston, MA: Wadsworth; 2011.

51. Kang H-S. Phonological variation in glides and diphthongs of Seoul Korean: Its synchrony and diachrony [Doctoral dissertation, Ohio State University] 1997.

52. Kim C-W. The vowel system of Korean. Language. 1968;44(3):516527.

53. Lee D-Y. Korean phonology: A principle-based approach. Munich, Germany: Lincom Europa; 1998.

54. Silva DJ. Phonological variation in Korean: The case of the "disappearing w". Language Variation and Change. 1991;3(2):153-170.

55. Zhu $\mathrm{H}$. The need for comparable criteria in multilingual studies. In: Zhu H, Dodd B, editors. Phonological development and disorders in children: A multilingual perspective. Clevedon, UK: Multilingual Matters; 2006. p. 15-22.

56. Goldstein BA. Assessing phonological skills in Hispanic/Latino children. Seminars in Speech and Language. 2001;22(1):39-49.

57. Kim MJ, Pae S. The percentage of consonants correct and the ages of consonantal acquisition for 'Korean-test of articulation for chil- dren (K-TAC)'. Korean Journal of Speech Science. 2005;12(2):139149.

58. Hong J, Pae S. Development of syllable-final consonants in children aged between 2 and 5 years. Korean Journal of Communication Disorders. 2002;7(2):294-304.

59. Pae S. Typical speech sound development (i): Children aged between 1;4 and 3;11. In: Korean Academy of Speech-Language Pathology \& Audiology, editor. Language disorders and treatment: Treatment of speech sound disorders in children. Seoul, Korea: Kunja Press; 1994. p. 27-53.

60. Um J. Typical speech sound development (ii): 3-, 4- and 5-yearold children. In: Korean Academy of Speech-Language Pathology \& Audiology, editor. Language disorders and treatment: Treatment of speech sound disorders in children. Seoul, Korea: Kunja Press; 1994. p. 54-66.

61. Jun H, Lee S. The development of Korean $/ \mathrm{s} /$ and $/ \mathrm{s}^{*} /$ in normal children of ages 2-7 years. Korean Journal of Communication Disorders. 1999;4:37-60.

62. James DGH, van Doorn J, McLeod S. Vowel production in mono-, di, and polysyllabic words in children aged 3;0 to 7;11 years. In: Wilson L, Hewat S, editors. Proceedings of the 2001 Speech Pathology Australia National Conference. Melbourne, Australia: Speech Pathology Australia; 2001. p. 127-135.

63. McIntosh B, Dodd BJ. Two-year-olds' phonological acquisition: Normative data. International Journal of Speech-Language Pathology. 2008;10(6):460-469.

64. Pollock KE, Berni MC. Incidence of non-rhotic vowel errors in children: Data from the Memphis Vowel Project. Clinical Linguistics \& Phonetics. 2003;17(4-5):393-401.

65. Park SJ. A study of vowel processes in children with normal language development and articulation disorders: Focused on vowel substitution processes. The Korean Journal of Early Childhood Special Education. 2010;10(3):193-208.

66. Park S-H. A study on diphthong production characteristic of preschool children. Journal of Speech-Language \& Hearing Disorders. 2011;20(3):1-16.

67. Goldstein BA, Bunta F, Lange J, Rodriguez J, Burrows L. The effects of measures of language experience and language ability on segmental accuracy in bilingual children. American Journal of SpeechLanguage Pathology. 2010;19:238-247.

68. Statistics New Zealand. 2013 New Zealand census of population and dwellings. Wellington, NZ: Statistics New Zealand; 2014.

69. Statistics New Zealand. New Zealand income survey. Wellington, NZ: Statistics New Zealand; 2014.

70. Kim J-H, Ballard E, McCann CM. Parent-rated measures of bilingual children's speech accuracy: Implications for a universal speech screen. International Journal of Speech-Language Pathology. 2016;18(2):202-211.

71. Bedore LM, Peña ED, Joyner D, Macken C. Parent and teacher rating of bilingual language proficiency and language development concerns. International Journal of Bilingual Education and Bilingualism. 2011;14(5):489-511.

72. Dodd B, Zhu H, Crosbie S, Holm A, Ozanne A. Diagnostic evaluation of articulation and phonology. London, UK: The Psychologi- 
cal Corporation; 2002.

73. Kim MJ, Pae S, Park C. Assessment of phonology and articulation for children. Incheon, Korea: Human Brain Research \& Consulting; 2007.

74. Andrews N, Fey ME. Analysis of the speech of phonologically impaired children in two sampling conditions. Language, Speech \& Hearing Services in Schools. 1986;17:187-198.

75. Goldstein BA, Fabiano L, Iglesias A. Spontaneous and imitated productions in Spanish-speaking children with phonological disorders. Language, Speech \& Hearing Services in Schools. 2004; 35:5-15.

76. Siegel S. Nonparametric statistics for the behavioral sciences. New York, NY: McGraw-Hill; 1956.

77. Keene ON. The log transformation is special. Statistics in Medicine. 1995;14:811-819.

78. Place S, Hoff E. Properties of dual language exposure that influence 2-year-olds' bilingual profiency. Child Development. 2011; 82:1834-1849.

79. Fischer C, Church BA, Chambers KE. Learning to identify spoken words. In: Hall DG, Waxman SR, editors. Weaving a Lexicon. Cambridge, MA: MIT Press; 2004. p. 3-40.

80. Richtsmeier PT, Gerken L, Goffman L, Hogan T. Statistical frequency in perception affects children's lexical production. Cognition. 2009;111(3):372-327.

81. Kim MJ. The phonological error patterns of preschool children in the 'Korean test of articulation for children'. Korean Journal of Communication Disorders. 2006;11(2):17-31.

82. Ellis R. The study of second language acquisition. 2nd ed. Oxford, UK: Oxford University Press; 2008.

83. Goldstein BA, Washington PS. An initial investigation of phonological patterns in typically developing 4-year-old Spanish-English bilingual children. Language, Speech, and Hearing Services in Schools. 2001;32(3):153-164.

84. Kim J-H, Ballard E, McCann CM. Age-related changes in segmental accuracy and error production in Korean-English bilingual children: Implications for clinical speech sound assessment procedures. Speech, Language and Hearing. 2017:Advance Online Publication. 